\title{
Article \\ Screening for Microbial Metal-Chelating Siderophores for the Removal of Metal Ions from Solutions
}

\author{
Marika Hofmann ${ }^{1, *}$, Thomas Heine ${ }^{1}(0)$, Luise Malik ${ }^{1}$, Sarah Hofmann ${ }^{1}$, Kristin Joffroy ${ }^{1}$, \\ Christoph Helmut Rudi Senges ${ }^{2}$, Julia Elisabeth Bandow ${ }^{2}$ and Dirk Tischler ${ }^{3, *(1)}$
}

1 Institute of Biosciences, TU Bergakademie Freiberg, 09599 Freiberg, Germany; heinethomas@ymail.com (T.H.); luise.malik@student.tu-freiberg.de (L.M.); hofmannsarah@aol.com (S.H.); kristin.friebel@student.tu-freiberg.de (K.J.)

2 Applied Microbiology, Faculty of Biology and Biotechnology, Ruhr-Universität Bochum, 44780 Bochum, Germany; Christoph.senges@rub.de (C.H.R.S.); julia.bandow@rub.de (J.E.B.)

3 Microbial Biotechnology, Faculty of Biology and Biotechnology, Ruhr-Universität Bochum, 44780 Bochum, Germany

* Correspondence: marika.hofmann90@gmail.com (M.H.); dirk.tischler@rub.de (D.T.)

check for

updates

Citation: Hofmann, M.; Heine, T.; Malik, L.; Hofmann, S.; Joffroy, K.; Senges, C.H.R.; Bandow, J.E.;

Tischler, D. Screening for Microbial Metal-Chelating Siderophores for the Removal of Metal Ions from Solutions. Microorganisms 2021, 9, 111. https://doi.org/10.3390/ microorganisms 9010111

Received: 18 December 2020 Accepted: 30 December 2020 Published: 5 January 2021

Publisher's Note: MDPI stays neutral with regard to jurisdictional clai$\mathrm{ms}$ in published maps and institutional affiliations.

Copyright: (C) 2021 by the authors. Licensee MDPI, Basel, Switzerland. This article is an open access article distributed under the terms and conditions of the Creative Commons Attribution (CC BY) license (https:// creativecommons.org/licenses/by/ $4.0 /)$.

\begin{abstract}
To guarantee the supply of critical elements in the future, the development of new technologies is essential. Siderophores have high potential in the recovery and recycling of valuable metals due to their metal-chelating properties. Using the Chrome azurol S assay, 75 bacterial strains were screened to obtain a high-yield siderophore with the ability to complex valuable critical metal ions. The siderophore production of the four selected strains Nocardioides simplex 3E, Pseudomonas chlororaphis DSM 50083, Variovorax paradoxus EPS, and Rhodococcus erythropolis B7g was optimized, resulting in significantly increased siderophore production of N. simplex and R. erythropolis. Produced siderophore amounts and velocities were highly dependent on the carbon source. The genomes of $N$. simplex and P. chlororaphis were sequenced. Bioinformatical analyses revealed the occurrence of an achromobactin and a pyoverdine gene cluster in P. chlororaphis, a heterobactin and a requichelin gene cluster in R. erythropolis, and a desferrioxamine gene cluster in N. simplex. Finally, the results of the previous metal-binding screening were validated by a proof-of-concept development for the recovery of metal ions from aqueous solutions utilizing $\mathrm{C}_{18}$ columns functionalized with siderophores. We demonstrated the recovery of the critical metal ions V(III), Ga(III), and In(III) from mixed metal solutions with immobilized siderophores of $N$. simplex and R. erythropolis.
\end{abstract}

Keywords: metallophore; screening; CAS assay; immobilization; metal binding; metal revocery

\section{Introduction}

Due to the continuously growing world population and the increasing competition with emerging economies for resources, the industrial nations have to face new challenges in terms of securing their raw materials supply. The supply of valuable metals is significantly dependent on their occurrence, existing resources, given processing methods, and recycling possibilities. Consequently, the development of new processes that allow metal extraction from low concentrated solutions or recycling material is gaining in importance [1]. Metal-loaded wastewater discharged from manufacturing and industrial processes poses an environmental threat if not properly treated [2]. Siderophores and other natural chelators possess promising metal-binding characteristics that provide a high potential for utilization in metal extraction processes and treatment of metal-loaded waters. These low molecular weight compounds have been reported to complex different kinds of metals including valuable metals (e.g., rare earth elements (REE), actinides, Ga, In, V, Co, noble metals) and contaminating metals (e.g., Pd, Ni, Cd, U) [3,4]. Well-described siderophores are, for example, the desferrioxamines of mainly actinobacteria, yersiniabactin of proteobacteria, and pyoverdine and pyochelin of pseudomonads [5]. The affinities to 
different metal ions depend on the structural characteristics of the functional groups responsible for metal binding as well as cationic size and ionic charge. Although siderophores containing sulfur and nitrogen-based metal binding motifs have been reported to exhibit exceptional affinities to divalent ions like $\mathrm{Cu}(\mathrm{II}), \mathrm{Zn}(\mathrm{II})$, and $\mathrm{Ni}(\mathrm{II})$ [6-9], the primary functional groups are oxygen-containing hydroxamate, catecholate, and carboxylate residues. Therefore, most siderophores show a strong preference for trivalent over divalent ions [4].

Many siderophores have been characterized and suggested for different applications, but a major challenge for an effective application is the reusability of the chelators because of their cost-intensive production and purification. Additionally, a precise application often requires to immobilize the soluble siderophores. For the implementation of this strategy, the siderophore itself or the whole producing cell is embedded, attached, linked, or entrapped on or in a solid material. A whole cell embedment was reported with pseudomonads and rhizobacteria in Ca-alginate beads or electrospun nanofibers, where the cells were protected against toxic compounds and grown under iron-limiting conditions [10-12]. The successful immobilization to a sol-gel matrix has been shown for pyoverdine, parabactin, and azotobactin aiming the use as biosensors [13-15]. Furthermore, desferrioxamine was attached to silica films through anhydride silane or amid linker molecules $[16,17]$ or embedded in silica-based mesocellular foam carriers [18]. Other immobilization attempts involve normal or activated forms of agarose or sepharose gels or beads [19-21]. Recently, the utilization of columns packed with siderophore-loaded polymeric XAD-16 resin was reported. Metals $(\mathrm{Co}, \mathrm{Mg}$, and $\mathrm{Ni})$ from industrial wastewaters were removed by means of the siderophore yersiniabactin and enabled a continuous and economical process [22].

Herein, we report the search for suitable metal-chelating siderophores, which could be applied for the recovery of valuable metals, starting from a screening of over 70 strains for siderophore production as well as metal binding and ending up with siderophore-loaded solid-phase extraction columns in laboratory scale.

\section{Materials and Methods}

All chemicals and supplements used were retrieved from Carl Roth (Karlsruhe, Germany), Sigma Aldrich (Darmstadt, Germany), Thermo Fisher (Kandel, Germany), Merck (Darmstadt, Germany).

\subsection{Bacterial and Fungal Strains and Isolation of Siderophore-Producing Bacteria}

Some of the strains used for the siderophore screening were retrieved from the German strain collection (DSMZ); others were retrieved from the strain collection of the Institute of Bioscience in Freiberg. More information about origin/references of each strain can be found in Table 1 and Table S1. Furthermore, bacteria were isolated from a heap in Neuhilbersdorf (strains H1-H3, 50 55'07.1" N 12²2'19.2" E, 2016/12/13), the sludge inside the mine drainage Roter Graben in Tuttendorf (strains RGS1-RGS4, 50 $56^{\prime} 24.1^{\prime \prime} \mathrm{N}$ $13^{\circ} 22^{\prime} 19.6^{\prime \prime}$ E, 2017/01/08) and wet soil next to Roter Graben (strain RGB, 2017/01/08). $1 \mathrm{~g}$ soil was suspended in $50 \mathrm{~mL}$ saline $(0.9 \% \mathrm{NaCl}$ solution) and incubated at room temperature over night while shaking. Thereafter, $100 \mu \mathrm{L}$ were plated onto CAS (Chrome azurol S) agar plates containing $100 \mathrm{mg} / \mathrm{L}$ cycloheximide. Colonies with big yellow halos were picked and transferred to a fresh plate in order to gain single colonies. If necessary, this procedure was repeated several times. Isolates obtained were stored as glycerol stocks for subsequent work.

\subsection{Cultivation and Siderophore Production}

Cells were cultivated in LB medium or a microorganism-specific medium. The screening experiments were carried out in culture tubes with $5 \mathrm{~mL}$ medium. For general siderophore production, precultures were grown three days in LB medium at $30^{\circ} \mathrm{C}$ with constant shaking at $120 \mathrm{rpm}$. Subsequently, cells were harvested by centrifugation $(5.000 \times g)$, washed three times with sterile saline, resuspended, and transferred to a minimal siderophore medium (SM) containing $12.8 \mathrm{~g} / \mathrm{L} \mathrm{Na} 2 \mathrm{HPO}_{4} \cdot 7 \mathrm{H}_{2} \mathrm{O}, 3 \mathrm{~g} / \mathrm{L} \mathrm{KH}_{2} \mathrm{PO}_{4}$, 
$0.5 \mathrm{~g} / \mathrm{L} \mathrm{NaCl}, 1 \mathrm{~g} / \mathrm{L} \mathrm{NH}_{4} \mathrm{Cl}, 10 \mathrm{~mL} / \mathrm{L}$ goodiemix, and a carbon source (e.g., $5 \mathrm{mM}$ glucose or benzoate). The goodiemix solution consists of $385 \mathrm{mM} \mathrm{MgSO}_{4}, 10 \mathrm{mM} \mathrm{CaCl}_{2}, 0.1 \mathrm{mM}$ thiamine, and $125 \mathrm{~mL} / \mathrm{L}$ trace element solution $\left(49 \mathrm{~g} / \mathrm{L} \mathrm{MgCl}_{2} \cdot 6 \mathrm{H}_{2} \mathrm{O}, 2 \mathrm{~g} / \mathrm{L} \mathrm{CaCO}_{4} 1.44 \mathrm{~g} / \mathrm{L}\right.$ $\mathrm{ZnSO}_{4} \cdot 7 \mathrm{H}_{2} \mathrm{O}, 0.85 \mathrm{~g} / \mathrm{L} \mathrm{MnSO}_{4} \cdot \mathrm{H}_{2} \mathrm{O}, 0.24 \mathrm{~g} / \mathrm{L} \mathrm{CuSO}_{4} \cdot 5 \mathrm{H}_{2} \mathrm{O}, 0.06 \mathrm{~g} / \mathrm{L} \mathrm{H}_{3} \mathrm{BO}_{3}, 51.3 \mathrm{~mL} / \mathrm{L}$ $\mathrm{HCl}$ ). To monitor siderophore production with the CAS assay, a low phosphate variant of the SM medium (SM-PP medium) containing only $10 \%$ of the typical phosphate concentration $\left(1.28 \mathrm{~g} / \mathrm{L} \mathrm{Na}_{2} \mathrm{HPO}_{4} \cdot 7 \mathrm{H}_{2} \mathrm{O}\right.$ and $\left.0.3 \mathrm{~g} / \mathrm{L} \mathrm{KH}_{2} \mathrm{PO}_{4}\right)$ was used to avoid interference with the assay solution. Some of the siderophore production experiments with selected strains were carried out in shaking flasks with $50 \mathrm{~mL}$ to $1 \mathrm{~L}$ medium. To investigate the light sensitivity of the siderophore/siderophore production of $V$. paradoxus, some culture tubes were lighted, while others were wrapped in aluminum foil. Lighting was realized by installing a natural light lamp ( $25 \mathrm{~W}$, Exo Terra) in front of the incubator. All siderophore production experiments were performed using $\mathrm{HCl}(6 \mathrm{M})$ washed glassware or plastic containers to avoid iron contamination [23].

\subsection{Chrome Azurol S Assay}

Siderophore production was monitored using the Chrome azurol S assay as CAS agar plates as well as the liquid assay. The CAS agar plates were prepared as described in literature [24,25]. The composition of the used liquid CAS assay solution was based on the standard iron CAS assay described in 1987 with some modifications [24,26]. To screen for metal-binding ability of the siderophores, CAS assay solutions with different metals ( $\mathrm{Al}$, $\mathrm{Ga}, \mathrm{Cu}$, and $\mathrm{V}$ ) were used. The preparation of the standard iron CAS assay solutions, the metal CAS assay solutions, and the assay procedure were performed as described previously [27-29]. In order to allow a proper determination of the siderophore concentration, control reactions of medium, buffer, or eluent were prepared in all cases. If the medium showed interference with the CAS assay, the blank sample and corresponding supernatant sample was diluted with $\mathrm{ddH}_{2} \mathrm{O}$ (e.g., $\mathrm{SM}$ medium was diluted 1:5). The calibration of the CAS assay solutions with known concentrations of DFOB (as desferrioxamine mesylate salt) allowed a semiquantitative siderophore determination in form of DFOB equivalent $\left(\mathrm{DFOB}_{\mathrm{eq}}\right)$ [28].

\subsection{Siderophore Extraction and MS Analysis}

Bacterial cells were removed from culture media by centrifugation $(10,000 \times g, 10-25 \mathrm{~min})$ followed by vacuum filtration $(0.45$ or $0.22 \mu \mathrm{m})$. The cell-free, siderophore-rich culture supernatants were adjusted to $\mathrm{pH} 6.0$ and extracted using a mixture of XAD-4 and XAD-16 (each $5 \mathrm{~g}$ per liter culture supernatant) while stirring at $4{ }^{\circ} \mathrm{C}$. After $20-30 \mathrm{~h}$, the XAD was separated by filtration and siderophores were eluted using a defined volume of methanol. The obtained siderophore extract was concentrated by rotary evaporation at $30^{\circ} \mathrm{C}, 180 \mathrm{rpm}$, and $90 \mathrm{mbar}$ to the desired concentration. Culture supernatants and siderophore extracts were stored at $4{ }^{\circ} \mathrm{C}$. Extracts and supernatants of $V$. paradoxus were additionally covered from light. The siderophore concentration was monitored over the time of storage.

High-resolution mass spectrometry (HRMS) data were acquired from samples of $V$. paradoxus EPS as follows. The data were acquired using a Waters Synapt G2-S HDMS with an electrospray ionization source and a time-of-flight detector. Samples were diluted 1:10 in acetonitrile with $0.1 \%$ formic acid and injected by direct infusion with a flow of $5 \mu \mathrm{L} / \mathrm{min}$. Spectra were recorded in $\mathrm{MS}^{\mathrm{E}}$ positive mode over a mass range of 50 to $3000 \mathrm{~m} / \mathrm{z}$ with $0.5 \mathrm{~s}$ per scan and leucin enkephalin injected as a reference mass every $30 \mathrm{~s}$. Continuous $\mathrm{MS}^{\mathrm{E}}$ spectra were recorded for $1 \mathrm{~min}$ with argon as collision gas and a collision energy ramp of 14-45 V. Used parameters: lockspray capillary voltage $2.5 \mathrm{kV}$, capillary voltage $2.5 \mathrm{kV}$, cone voltage $30 \mathrm{~V}$, source temperature $120^{\circ} \mathrm{C}$, cone gas flow $60 \mathrm{~L} / \mathrm{h}$, flushing gas flow $550 \mathrm{~L} / \mathrm{h}$ with a temperature of $150{ }^{\circ} \mathrm{C}$. Fragment spectra were recorded in data-dependent acquisition positive mode over an energy ramp 10-25 V. The remaining parameters were used as described for $\mathrm{MS}^{\mathrm{E}}$ mode. 
In case of samples derived from strains $R$. erythropolis $\mathrm{B} 7 \mathrm{~g}$ and $N$. simplex $3 \mathrm{E}$, the procedure was adapted, and the instrumental setup was changed. Analytes were eluted from the XAD resin by addition of $5 \mathrm{~mL}$ of methanol and shaking for $10 \mathrm{~min}$ at $40 \mathrm{rpm}$. The resin was removed by centrifugation $(10,000 \times g, 10 \mathrm{~min})$ and the extract diluted 1:10 in 50:50 mixture of water and acetonitrile (ACN).

Of these samples, $5 \mu \mathrm{L}$ were injected on an ACQUITY UPLC I-Class System (Waters, Milford, Massachusetts) equipped with an ACQUITY PREMIER HSS T3 column (particle size $1.8 \mu \mathrm{m}$, column dimensions: $2.1 \times 100 \mathrm{~mm}$ ). A gradient with $\mathrm{H}_{2} \mathrm{O}$ and $\mathrm{ACN}$, each with $0.1 \%$ formic acid (FA), was used with a flow rate of $0.6 \mathrm{~mL} / \mathrm{min}$ (Table S4).

Data-independent $\mathrm{MS}^{\mathrm{E}}$ measurements were performed with a Vion IMS QToF (Waters) with an ESI source in positive sensitivity mode. Masses in a range of 50 to $2000 \mathrm{~m} / \mathrm{z}$ were detected with $0.1 \mathrm{~s}$ per scan and leucine enkephalin being injected as a reference mass every $5 \mathrm{~min}$. Used parameters: capillary voltage $0.8 \mathrm{kV}$, sample cone voltage $40 \mathrm{~V}$, source offset voltage $80 \mathrm{~V}$, cone gas flow $50 \mathrm{~L} / \mathrm{h}$, desolvation gas flow $1000 \mathrm{~L} / \mathrm{h}$, source temperature $150{ }^{\circ} \mathrm{C}$, desolvation temperature $550{ }^{\circ} \mathrm{C}$, collision gas $\mathrm{N}_{2}$, collision low energy $6 \mathrm{~V}$, collision high energy ramp 28-60 V. Putative siderophores were identified through matching of parent masses and comparison of fragment spectra to in silico fragmentation.

\subsection{Screening and Optimization}

The siderophore production of $>70$ different strains was screened, including known microorganisms and soil isolates. The strains were grown in LB medium for three days. Cells were washed and transferred to reaction tubes with $5 \mathrm{~mL}$ SM-PP containing $20 \mathrm{mM}$ glucose. Samples were taken after three, five, and nine days and siderophore production was measured in the supernatant using the liquid CAS assay. Some strains were further tested with CAS assay solutions containing $\mathrm{Al}, \mathrm{Ga}, \mathrm{Cu}$, or $\mathrm{V}$ instead of Fe. After the selection of four interesting bacteria, their siderophore production was optimized and scaled up to $100 \mathrm{~mL}$ or $1 \mathrm{~L}$. The bacteria were grown on different carbon sources $(5 \mathrm{mM}$ glucose, $5 \mathrm{mM}$ benzoate, $5 \mathrm{mM}$ succinate, and/or $2.5 \mathrm{mM} n$-hexadecane) and supplied with casamino acids in different concentrations $(0 \%, 0.2 \%, 0.5 \%$, and $1.0 \%$, and in case of R. erythropolis, additionally $1.5 \%$ and $2.0 \%$ ). Samples were taken frequently over a period of up to 21 days.

\subsection{Immobilization Procedure and Application to Metal-Loaded Solutions}

For immobilization and metal-binding experiments, cells from LB precultures of R. erythropolis B7g, V. paradoxus EPS, N. simplex 3E, and P. chlororaphis DSM 50083 were washed and transferred 1:2 or 1:5 to $1 \mathrm{~L} \mathrm{SM-PP.} 5 \mathrm{~mL}$ benzoate was added as carbon source for $V$. paradoxus, P. chlororaphis and N. simplex. R. erythropolis was additionally supplied with $0.2 \%$ casamino acids. In the case of $R$. erythropolis $\mathrm{B} 7 \mathrm{~g}$, cells were cultivated with $20 \mathrm{mM}$ glucose, $2.5 \mathrm{mM} n$-hexadecane, and $0.1 \%$ casamino acids. Siderophore concentration was monitored with the standard CAS assay. Siderophore-containing culture supernatants were separated from cells by centrifugation, adjusted to $\mathrm{pH} 2.0$ using $\mathrm{HCl}$, and applied to preconditioned $\mathrm{C}_{18}$ solid-phase extraction columns $\left(100 \mathrm{mg}\right.$, HyperSep ${ }^{\mathrm{TM}}$, Thermo Scientific) with 250 mbar via a Biotage ${ }^{\circledR}$ VacMaster (Uppsala, Schweden) (Figure S1). Depending on the siderophore concentration and the binding capacity of the column material identified in previous studies, $40 \mathrm{~mL}$ (R. erythropolis, P. chlororaphis) or $30 \mathrm{~mL}$ (N. simplex) culture supernatant were loaded onto the column. The siderophore concentration in the flow-through was detected to calculate the amount of siderophore attached to the column. Siderophore-containing flow-through was repetitively loaded to the columns up to four times followed by a washing step with $\mathrm{ddH}_{2} \mathrm{O}$ acidified with $\mathrm{HCl}$ to $\mathrm{pH}$ 2.0. The multiple loading ensured later binding of passed-through siderophore to the binding side, which were still idle after first applications. Moreover, the repetitive loading created a better distribution of the substance through the whole column. The metal-binding ability of the immobilized siderophore was examined using metal solutions of $\mathrm{FeCl}_{3} \cdot 6 \mathrm{H}_{2} \mathrm{O}$, $\mathrm{Ga}_{2}\left(\mathrm{SO}_{4}\right)_{3} \cdot \mathrm{H}_{2} \mathrm{O}, \mathrm{AlCl}_{3} \cdot 6 \mathrm{H}_{2} \mathrm{O}, \mathrm{CrCl}_{3} \cdot 6 \mathrm{H}_{2} \mathrm{O}, \mathrm{NdCl}_{3} \cdot \mathrm{H}_{2} \mathrm{O}, \mathrm{CeCl}_{3} \cdot \mathrm{H}_{2} \mathrm{O}, \mathrm{VCl}_{3}, \mathrm{InCl}_{3}$, and 
$\mathrm{LaCl}_{3} \cdot 7 \mathrm{H}_{2} \mathrm{O}$ in different concentrations and compositions. Therefore, the metal solutions were applied to the siderophore-loaded columns, incubated for $30 \mathrm{~min}$ at room temperature and eluted. Unloaded columns were treated the same way to function as blank samples. The flow-through was collected, a sample adjusted to $1 \%$ nitric acid and analyzed by inductively coupled plasma mass spectrometry (ICP-MS, xseries 2, Thermo Scientifc, Dreieich, Germany) [30]. All experiments were done in duplicate. A summarizing and visualizing graphic of the workflow can be found in Figure S2.

\subsection{Genome Sequencing and Siderophore Gene Cluster}

The genome of $R$. erythropolis B7g and $V$. paradoxus EPS were published previously [31,32]. The genomic DNA of $N$. simplex 3E and the type strain P. chlororaphis DSM 50083 were isolated using an adapted phenol-chloroform method as described previously [31]. The preparation of the library, genome sequencing, assembly annotation, and analysis were done as described elsewhere [31,33].

To identify the siderophore biosynthesis gene clusters, annotation was performed using antiSMASH 5.0 [34,35] and RAST 2.0 [36-38]. The amino acid sequences of some key enzymes were used as queries for BLAST searches within the genome.

\section{Results}

\subsection{Siderophore Screening}

The siderophore production and metal-binding ability of several bacterial and fungal strains were examined in order to identify good siderophore producers $(\geq 100 \mu \mathrm{M}$ $\mathrm{DFOB}_{\mathrm{eq}}$ ), which can be applied to treat metal-loaded solutions. In a first screening, 72 strains were tested on solid CAS agar plates and/or with the liquid standard CAS assay for their siderophore production (Table 1 and Table S1). Except for Oerskovia sp. EDN3, Sphingopyxis panaciterrulae DSM 25122, and Sphingopyxis italica DSM 25299, all strains showed a positive reaction to at least one of the tests. However, the produced amount of siderophore $\left(\mathrm{DFOB}_{\mathrm{eq}}\right)$ detected with the liquid standard CAS assay varied from $10 \mu \mathrm{M}$ (Pseudomonas sp. RGS2) to $600 \mu \mathrm{M}$ (P. alliaceus DSM 813). 22 strains produced $\geq 100 \mu \mathrm{M}$ siderophore $\left(\mathrm{DFOB}_{\mathrm{eq}}\right.$ ) under the standard assay conditions, 12 strains more than $250 \mu \mathrm{M}$. After the first screening, 25 strains were selected for the next screening round focusing on the interaction with different CAS assay variants containing the metals $\mathrm{Al}$, $\mathrm{Ga}, \mathrm{Cu}$, or $\mathrm{V}$ instead of iron. The results are shown in Table 1. For better comparability between the strains and their different levels of siderophore production, the concentration of $\mathrm{DFOB}_{\mathrm{eq}}$ of the metal CAS experiments (Me-CAS) were divided by the concentration of $\mathrm{DFOB}_{\mathrm{eq}}$ of the standard Fe-CAS solution $\left(\mathrm{DFOB}_{\mathrm{eq}}(\mathrm{Me}-\mathrm{CAS}) / \mathrm{DFOB}_{\mathrm{eq}}(\mathrm{Fe}-\mathrm{CAS})\right.$ ) and symbolized. Three pluses (+++) indicate a better removal of the metal ion from the MeCAS complex than from the Fe-CAS complex. The reactions with the different CAS assay solutions were diverse among the tested stains. While the siderophores of $A$. aurescens, $R$. corynebacterioides, and T. agreste showed no noteworthy metal removal from the Me-CAS complexes, siderophores of Aspergillus niger, the tested Pseudomonas strains, R. erythropolis B7g, and Sphingomonas herbicidovorans seem to complex at least three of the four tested metals. Furthermore, the siderophores of rhodococci showed good results with the V-CAS assay, but in most cases, comparably less interaction with the other Me-CAS solutions. 
Table 1. Results of the screening of selected strains with different Chrome azurol S (CAS) assay solutions.

\begin{tabular}{|c|c|c|c|c|c|c|c|}
\hline Strain & Origin/Reference & CAS Agar Plates & $\begin{array}{c}\text { Standard Fe-CAS } \\
\left(\mathrm{DFOB}_{\mathrm{eq}}\right)\end{array}$ & Al-CAS & Ga-CAS & Cu-CAS & V-CAS \\
\hline \multicolumn{8}{|l|}{ Fungi } \\
\hline Aspergillus niger DSM 821 & DSMZ & n.d. & $++(180 \mu \mathrm{M})$ & +++ & +++ & +++ & +++ \\
\hline Penicillium griseofulvum DSM 896 & DSMZ & n.d. & $+(90 \mu \mathrm{M})$ & + & - & +++ & + \\
\hline Petromyces alliaceus DSM 813 & DSMZ & n.d. & $+++(600 \mu \mathrm{M})^{\mathrm{b}}$ & ++ & ++ & + & + \\
\hline \multicolumn{8}{|l|}{ Bacteria } \\
\hline Arthrobacter aurescens TC1 & Local strain collection, [39] & ++ & $+++(280 \mu \mathrm{M})$ & + & + & + & + \\
\hline Gordonia rubripertincta CWB 2 DSM 46758 & Local strain collection, isolated from soil $[40,41]$ & $+a$ & $+(70 \mu \mathrm{M})$ & ++ & + & +++ & n.d. \\
\hline Nocardioides simplex $3 \mathrm{E}$ & Local strain collection, [42] & ++ & $+++(340 \mu \mathrm{M})$ & + & - & ++ & $(+)$ \\
\hline Oerskovia sp. SPF2 & Local strain collection, isolated from soil [40] & + & $++(170 \mu \mathrm{M})$ & ++ & + & + & ++ \\
\hline Paracoccus denitrificans DSM 413 & DSMZ & +++ & $+++(400 \mu \mathrm{M})$ & + & + & ++ & ++ \\
\hline Pseudomonas sp. RGS3 & Soil isolate, unpublished & +++ & $+(85 \mu \mathrm{M})$ & ++ & - & +++ & ++ \\
\hline Pseudomonas sp. RGS4 & Soil isolate, unpublished & +++ & $++(110 \mu \mathrm{M})$ & +++ & - & ++ & ++ \\
\hline Pseudomonas sp. RGB & Soil isolate, [33] & +++ & $++(110 \mu \mathrm{M})$ & ++ & ++ & +++ & +++ \\
\hline Pseudomonas sp. H1 & Soil isolate, unpublished & +++ & $++(140 \mu \mathrm{M})$ & +++ & + & ++ & ++ \\
\hline Pseudomonas sp. H3 & Soil isolate, [33] & + & $+(60 \mu \mathrm{M})$ & +++ & + & +++ & ++ \\
\hline Pseudomonas chlororaphis DSM 50083 & DSMZ & n.d. & $++(110 \mu \mathrm{M})$ & + & ++ & +++ & ++ \\
\hline Rhodococcus corynebacterioides DSM 20151 & DSMZ & + & $+++(270 \mu \mathrm{M})$ & + & + & + & + \\
\hline Rhodococcus erythropolis B7g & Local strain collection [31] & +++ & $+++(350 \mu \mathrm{M})$ & ++ & + & +++ & +++ \\
\hline Rhodococcus erythropolis S43 & Local strain collection $[29,44,45]$ & ++ & $++(160 \mu \mathrm{M})$ & + & + & + & +++ \\
\hline Rhodococcus jostii RHA1 & {$[46]$} & +++ & $++(100 \mu \mathrm{M})$ & ++ & + & +++ & n.d. \\
\hline Rhodococcus opacus 1CP, DSM 46757 & DSMZ [47] & ++ & $++(150 \mu \mathrm{M})$ & ++ & + & ++ & n.d. \\
\hline Rhodococcus ruber DSM 8425 & DSMZ & ++ & $++(230 \mu \mathrm{M})$ & + & + & + & +++ \\
\hline Sphingomonas herbicidovorans DSM 11019 & DSMZ & ++ & $++(110 \mu \mathrm{M})$ & ++ & +++ & +++ & + \\
\hline Thermocrispum agreste DSM 44070 & DSMZ & $++{ }^{c}$ & $+++(300 \mu \mathrm{M})^{c}$ & n.d. & + & + & + \\
\hline Variovorax paradoxus EPS & $\begin{array}{l}\text { Local strain collection, P. Orwin, personal } \\
\text { communication, [32] }\end{array}$ & ++ & $+++(470 \mu \mathrm{M})$ & + & ++ & +++ & + \\
\hline
\end{tabular}

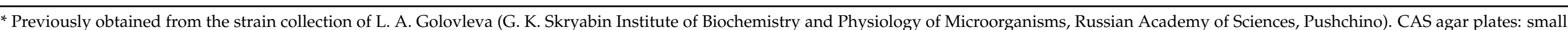

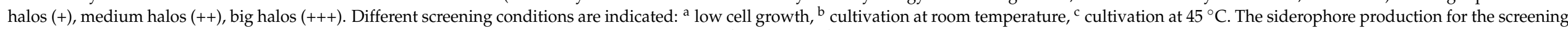

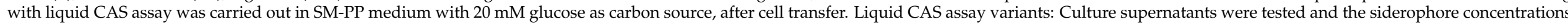

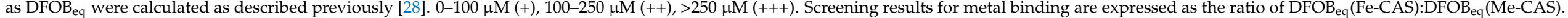

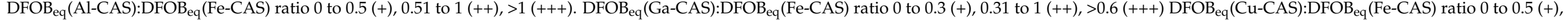
0.51 to $1(++),>1(+++)$. $\mathrm{DFOB}_{\mathrm{eq}}(\mathrm{V}-\mathrm{CAS}): \mathrm{DFOB}_{\mathrm{eq}}(\mathrm{Fe}-\mathrm{CAS})$ ratio 0 to $0.5(+), 0.51$ to $1(++),>1(+++)$. 
Four strains were selected for further investigations: R. erythropolis B7g, N. simplex 3E, $P$. chlororaphis, and $V$. paradoxus EPS produced good or very good amounts of siderophores (compared with Table 1) under assay conditions and showed different metal interaction profiles. Additionally, the strains showed good homogeneous growth and were easy to handle, which were criteria for later applications. The strains belong to different genera and produce different types of siderophores, which increased the chance to find a suitable siderophore for the attachment to solid-phase extraction columns. Next to the aforementioned strains, the bacteria T. agreste DSM 44070, G. rubripertincta CWB2, and R. erythropolis S43 were investigated separately and the results were published elsewhere $[18,29,48,49]$.

\subsection{Genome Sequencing and Prediction of the Produced Siderophore}

The structures of the siderophores produced by the selected bacterial strains were not identified before. However, siderophores of representatives of pseudomonads, rhodococci, Nocardioides sp., and Variovorax sp., and the corresponding siderophore biosynthesis gene clusters are well known. The comparison of the siderophore gene clusters of our selected strains to gene clusters of biochemically and structurally described siderophores enables the estimation of the produced siderophores and their basic characteristics without the necessity of extensive purification and structure determination.

Using RAST and antiSMASH for annotation, we were able to identify two putative siderophore biosynthesis gene clusters in the genome of R. erythropolis B7g (Figure S3). Both of them exhibit strong homology to gene clusters known from other rhodococci, especially strain R. erythropolis PR4. The first one is identified as a heterobactin biosynthesis cluster, while the respective CDS provide an identity of $96 \%$ to $100 \%$ on protein level to those from strain PR4 [50]. Heterobactins are mixed-type catecholate-hydroxamate siderophores. The second gene cluster shows homology to previously described requichelin clusters (sequence id. $95 \%$ to $100 \%$ ), whose siderophore is similar to erythrochelin and foroxymithine. However, the respective siderophore has not been characterized in detail so far [50,51]. In order to verify the prediction from the genome strain, B7g was cultivated in SM-PP medium comprising $20 \mathrm{mM}$ glucose, $2.5 \mathrm{mM}$-hexadecane and $1 \%$ casamino acids (which was a result from the below shown optimization of siderophore production). Three biological replicates were cultivated (for 4 days) and yielded 181 to $260 \mu \mathrm{M} \mathrm{DFOB}$ eq prior or 35 to $55 \mu \mathrm{M} \mathrm{DFOB}$ eq after XAD extraction in culture broth, respectively. Hence, most of the siderophores were successfully extracted. Thereof, the siderophore was eluted and analyzed by means of HRMS in order to identify the main siderophore component. The results clearly demonstrated the presence of heterobactin B and apo-heterobactin S2 according to the measured $m / z$ values 438.197 and 694.212 $\mathrm{Da}[\mathrm{M}+\mathrm{H}]^{+}$, respectively (Table S6). Those fit to the theoretical value and the fragmentation supported this annotation.

Representatives of the genus Variovorax have been described to produce the four carboxylate-hydroxamate siderophores variochelin, imaqobactin, variobactin, and vacidobactin and some derivates [52-54]. The putative siderophore gene cluster and biosynthetic modules of $V$. paradoxus EPS were identified a few years ago (Figure S4). This bioinformatic analysis indicated that structural features (such as $N$-hydroxamate moieties) known from other Variovorax siderophores are likely to be present in the siderophore of strain EPS [53]. Compared to the gene clusters of variobactin- and vacidobactin- producing bacteria, the siderophore gene cluster of V. paradoxus EPS differs in size and gene organization, indicating a larger siderophore. To prove the suggestion, we isolated the siderophore and analyzed it using mass spectrometry. The analysis showed two main signals indicating two molecules with a measured $m / z$ of 1161.5248 and $1176.5262 \mathrm{Da}[\mathrm{M}+\mathrm{H}]^{+}$(Figure S5).

Since there were no genome data available for N. simplex 3E and P. chlororaphis DSM 50083 at the beginning of our study, the genomic DNA of the two strains was isolated and sequenced to receive the necessary data. This whole genome shotgun project was deposited at DDBJ/ENA/GenBank under the accession JADCLH000000000 (P. chlororaphis, BioSample SAMN16418570) and JADCLI000000000 (N. simplex, BioSample SAMN16418572). The versions described in this paper are version JADCLH010000000 and JADCLI010000000, 
respectively. Recently, a complete genome sequence of $P$. chlororaphis DSM 50083 was uploaded to Genbank under the accession number CP027712.1. The authors used another sequencing method, and no publication is available yet. The results of both sequencing experiments are compared in Table S2.

A genome coverage of 210x for strain Nocardioides simplex 3E and 407x for strain Pseudomonas chlororaphis DSM 50083 was obtained, respectively. The results of the genome sequencing are summarized in Table 2. For isolate 3E, 83 contigs ( $\geq 3000 \mathrm{bp}$ ) were identified that cover about $5.4 \mathrm{Mbp}$ with an average $\mathrm{G}+\mathrm{C}$ content of 72\% (N50 = 102286; N75 = 61207; $\mathrm{L} 50=18 ; \mathrm{L} 75=36)$. For the strain DSM 50083, the assembly resulted in 35 contigs ( $\geq 3000 \mathrm{bp})$ covering about $6.8 \mathrm{Mbp}$ with an average $\mathrm{G}+\mathrm{C}$ content of $63 \%(\mathrm{~N} 50=404628 ; \mathrm{N} 75=237024$; $\mathrm{L} 50=6$; L75 = 12). A 16S rDNA-based phylogenetic analysis was implemented for both isolates in order to verify the closest relatives (Figures S6 and S7). Pseudomonas chlororaphis DSM 50083 clusters, as expected, together with the other chlororaphis strains (Figure S6).

Table 2. Genome statistics of the genome sequenced strains.

\begin{tabular}{ccc}
\hline Genome Feature & Nocardioides simplex 3E & $\begin{array}{c}\text { Pseudomonas chlororaphis } \\
\text { DSM 50083 }\end{array}$ \\
\hline Sum of contig length $(\mathrm{bp})$ & $5,365,546$ & $6,771,389$ \\
Contigs & $83(>3000 \mathrm{bp})$ & $35(>3000 \mathrm{bp})$ \\
G + C content $(\%)$ & 72 & 63 \\
Protein coding genes & 5148 & 6128 \\
Average gene length $(\mathrm{bp})$ & 944 & 978 \\
Coding percentage $(\%)$ & 91 & 89 \\
tRNAs & 46 & 43 \\
rRNAs & 4 & 2 \\
\hline
\end{tabular}

Interestingly, Nocardioides simplex 3E does not form a branch with other simplex strains (Figure S7). To our knowledge, strain 3E has been assigned to the species simplex solely by morphological, physiological, and chemotaxonomic characters [42]; this might be a hint that a closer look at the classification is required.

The biological subsystem distribution of the annotated genes based on RAST can be found in Table 3 [37]. A subsystem coverage of 38\% and 53\% was achieved for N. simplex $3 \mathrm{E}$ and P. chlororaphis DSM 50083, respectively. Herein, $1.0 \%$ of the genes of the strain $3 \mathrm{E}$ and $2.9 \%$ of the genes of strain DSM 50083 are supposed to be related to iron acquisition and metabolism. For specification, a genome analysis was performed via antiSMASH to identify siderophore biosynthesis cluster [35].

For $P$. chlororaphis DSM 50083, 14 secondary metabolite clusters were identified. Three of those putatively contain siderophore related genes (cluster 4, 10, 13; Table 4). However, due to the fragmentation of the genome and inaccuracies of the in silico annotation, a manual curation was required. Therewith, gene clusters for the biosynthesis of achromobactin as well as pyoverdine were identified (Figures S8 and S9). The latter finding is supported by the fact that strain DSM 50083 produces a fluorescent siderophore (data not shown). While the achromobactin cluster is highly similar to the cluster of P. syringae B728a (Figure S8), the pyoverdine cluster shows homology to the one from $P$. fluorescens SBW25 [55]. In contrast, two of the NRPSs (Pflu 2552 and 2553) are not encoded in strain DSM 50083. However, the three NRPSs, which are required for biosynthesis of pyoverdine, are encoded [56]. As it is known, that the structure of pyoverdines is variable [57], further analysis is needed to reveal the subsequent structure of the pyoverdine of strain DSM 50083. However, in this study we were not able to effectively apply this siderophore in our column experiments and hence no more effort was put to solve the respective siderophore structure. 
Table 3. Biological subsystem distribution of annotated genes in N. simplex 3E and P. chlororaphis DSM 50083.

\begin{tabular}{|c|c|c|c|c|}
\hline \multirow[b]{2}{*}{ Subsystem Coverage } & \multicolumn{2}{|c|}{ Nocardioides simplex $3 \mathrm{E}$} & \multicolumn{2}{|c|}{$\begin{array}{c}\text { Pseudomonas chlororaphis } \\
\text { DSM } 50083\end{array}$} \\
\hline & $38 \%$ & & $53 \%$ & \\
\hline Description & Value & Percent & Value & Percent \\
\hline Cofactors, vitamins, prosthetic groups, pigments & 366 & 11.9 & 385 & 8.1 \\
\hline Cell wall and capsule & 76 & 2.5 & 232 & 4.9 \\
\hline Virulence, disease, and defense & 100 & 3.3 & 153 & 3.2 \\
\hline Potassium metabolism & 13 & 0.4 & 26 & 0.5 \\
\hline Miscellaneous & 39 & 1.3 & 91 & 1.9 \\
\hline Phages, prophages, transposable elements, plasmids & 5 & 0.2 & 37 & 0.8 \\
\hline Membrane transport & 116 & 3.8 & 310 & 6.5 \\
\hline Iron acquisition and metabolism & 31 & 1.0 & 137 & 2.9 \\
\hline RNA metabolism & 99 & 3.2 & 223 & 4.7 \\
\hline Nucleosides and nucleotides & 123 & 4.0 & 142 & 3.0 \\
\hline Protein metabolism & 267 & 8.7 & 287 & 6.0 \\
\hline Cell division and cell cycle & 8 & 0.3 & 33 & 0.7 \\
\hline Motility and chemotaxis & 61 & 2.0 & 117 & 2.5 \\
\hline Regulation and cell signaling & 46 & 1.5 & 163 & 3.4 \\
\hline Secondary metabolism & 8 & 0.3 & 8 & 0.2 \\
\hline DNA metabolism & 109 & 3.5 & 101 & 2.1 \\
\hline Fatty acids, lipids, and isoprenoids & 296 & 9.6 & 232 & 4.9 \\
\hline Nitrogen metabolism & 29 & 0.9 & 84 & 1.8 \\
\hline Dormancy and sporulation & 2 & 0.1 & 3 & 0.1 \\
\hline Respiration & 108 & 3.5 & 153 & 3.2 \\
\hline Stress response & 114 & 3.7 & 229 & 4.8 \\
\hline Metabolism of aromatic compounds & 76 & 2.5 & 161 & 3.4 \\
\hline Amino acids and derivatives & 502 & 16.3 & 783 & 16.4 \\
\hline Sulfur metabolism & 48 & 1.6 & 107 & 2.2 \\
\hline Phosphorus metabolism & 51 & 1.7 & 83 & 1.7 \\
\hline Carbohydrates & 378 & 12.3 & 493 & 10.3 \\
\hline
\end{tabular}

Table 4. Secondary metabolite clusters identified in P. chlororaphis DSM 50083 with antiSMASH 5.0.

\begin{tabular}{cccccc}
\hline Cluster & Type & From & To & Most Similar Known Cluster & Similarity \\
\hline 1 & Betalactone & 79,159 & 102,356 & Fengycin & - \\
2 & Butyrolactone & 398,878 & 409,684 & - & - \\
3 & Hserlactone, phenazine & 653,018 & 675,803 & Streptophenazine & $21 \%$ \\
4 & NRPS & 10,215 & 63,258 & Pyoverdin & - \\
5 & Hserlactone & 90,777 & 111,436 & - & - \\
6 & Bacteriocin & 267,812 & 278,636 & - & - \\
7 & NAGGN & 125,396 & 140,044 & - & $8 \%$ \\
8 & Bacteriocin & 263,712 & 274,605 & Ashimides & $18 \%$ \\
9 & NRPS & 371,707 & 421,496 & Vibrioferrin & $100 \%$ \\
10 & Siderophore & 474,501 & 493,491 & Pyrrolnitrin & $40 \%$ \\
11 & Other & 592,690 & 633,775 & APE Vf & $31 \%$ \\
12 & Arylpolyene & 184,548 & 228,168 & Pyoverdin & $60 \%$ \\
13 & NRPS, resorcinol & 122,372 & 205,824 & Fragin & \\
\hline
\end{tabular}

In 1968, an N. simplex strain was described to produce ferrioxamine B and the siderophore was isolated [58]. This is in accordance with the identified siderophore biosynthesis cluster (Table 5 and Figure S10), which encodes the required enzymes known to be responsible for DFOB production. The DFO gene cluster of strain $3 \mathrm{E}$ provides an identity of $76-88 \%$ on protein level to the gene cluster of strain VKM Ac-2033D, which has been described previously [59-61]. In order to verify the genomic analysis strain, $3 \mathrm{E}$ was cultivated in SM-PP medium containing $5 \mathrm{mM}$ benzoate and $1 \%$ casamino acids. 
The main cultures (three replicates) showed high siderophore titers after 4 days (486 to $549 \mu \mathrm{M} \mathrm{DFOB}_{\mathrm{eq}}$ ) and were extracted for a subsequent HRMS study. The remaining titer was less than $8 \mu \mathrm{M} \mathrm{DFOB}_{\mathrm{eq}}$ in the supernatant, and thus we can state the siderophores were almost fully extracted. Herein, four major compounds were identified, namely bisucaberin, desferrioxamine B, desferrioxamine D3 and desferrioxamine E, according to the observed masses given in Table S5; the identification using observed masses is supported by the reference compounds (theoretical masses) as well as abounded fragment masses.

Table 5. Secondary metabolite clusters identified in N. simplex 3E with antiSMASH 5.0.

\begin{tabular}{cccccc}
\hline Cluster & Type & From & To & Most Similar Known Cluster & Similarity \\
\hline 1 & NRPS-like & 27,311 & 69,866 & - & - \\
2 & Siderophore & 37,825 & 50,206 & Desferrioxamine & $50 \%$ \\
3 & NRPS-like & 78,561 & 122,328 & - & - \\
\hline
\end{tabular}

\subsection{Siderophore Production}

To increase the amount of produced siderophore, the previously chosen strains were tested for their siderophore production under different media supply conditions. Since the substrate is reported to have an influence on siderophore production [62,63], the cultures were grown with glucose, succinate, benzoate, or $n$-hexadecane and regularly tested with the standard CAS assay over several days. The optical density at the inoculation and at stationary stage was measured as reference for bacterial growth (Table S3). Furthermore, the effect of the supplementation with iron-free casamino acids was investigated.

Nocardioides simplex 3E showed the highest siderophore production with benzoate $\left(400 \mu \mathrm{M} \mathrm{DFOB}_{\mathrm{eq}}\right)$, followed by glucose $\left(280 \mu \mathrm{M} \mathrm{DFOB}_{\mathrm{eq}}\right)$ and succinate $\left(180 \mu \mathrm{M} \mathrm{DFOB}_{\mathrm{eq}}\right)$ (Figure S11A). However, siderophore production in benzoate-containing cultures started later than in the cultures with other substrates. It is noteworthy that the siderophore amount increased quickly in the beginning, decreased again after reaching a maximum, and stayed constant after some days. No siderophore could be detected in $n$-hexadecane-containing cultures due to an insufficient culture growth. The produced amount of siderophore increased significantly by the addition of casamino acids. The addition of $1 \%$ yielded in concentrations up to $1500 \mu \mathrm{M} \mathrm{DFOB}_{\text {eq }}$ (Figure 1A). Therefore, casamino acids were added to all further siderophore producing cultures of N. simplex.

The results of the siderophore biosynthesis of $P$. chlororaphis with different substrates were comparable to that of $N$. simplex regarding the preferred substrates, but the maximal concentrations were significantly lower for all substrates (highest amount was $150 \mu \mathrm{M}$, Figure 1B). A fast decrease of the produced siderophore amount could only be observed with benzoate as substrate.

The siderophore production of R. erythropolis B7g cultures yielded in much higher siderophore concentrations grown on SM (Figure 1C) than on SM-PP (Figure S11B) medium due to the higher phosphate supply. The maximal produced amount (up to $680 \mu \mathrm{M} \mathrm{DFOB}$ eq) was almost three times as high as in low-phosphate medium. Small scale preliminary experiments with R. erythropolis showed that no noteworthy siderophore production was achieved with succinate and benzoate. Cultures grown on $n$-hexadecane showed a faster siderophore production than on glucose but a much lower siderophore concentration in SM medium. However, the simultaneous addition of both glucose and $n$-hexadecane to the culture turned out to compensate the deficits of the single substrates, leading to a fast and high siderophore production (Figure 1C). The supplementation with $<1 \%(\mathrm{~m} / \mathrm{v})$ casamino acids and $30 \mathrm{mM}$ glucose in a $1 \mathrm{~L}$ culture was able to increase the siderophore concentration up to $2.2 \mathrm{mM} \mathrm{DFOB}_{\mathrm{eq}}$. 

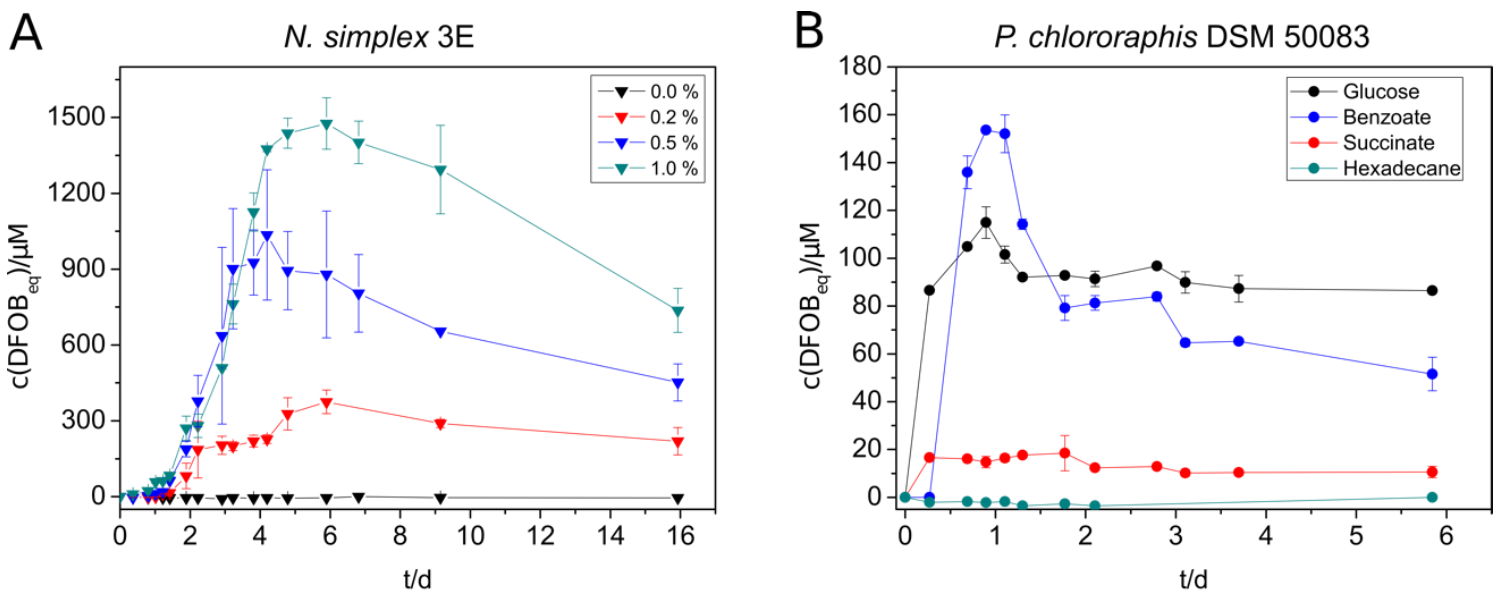

C R. erythropolis B7g

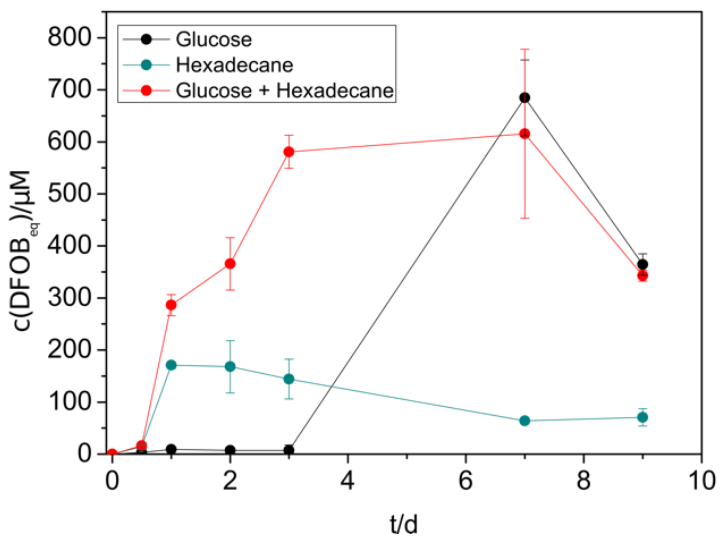

Figure 1. Siderophore production of selected strains under different cultivation conditions. (A) N. simplex 3E was supplied with different concentrations of casamino acids in SM-PP medium with $5 \mathrm{mM}$ benzoate. (B) Siderophore production of P. chlororaphis DSM 50083 in SM-PP (siderophore medium with low phosphate content) with 5 mM succinate, benzoate, glucose, or $2.5 \mathrm{mM} n$-hexadecane. C: $R$. erythropolis B7g cultures in SM medium were grown in either $20 \mathrm{mM}$ glucose, $2.5 \mathrm{mM}$ $n$-hexadecane, or $20 \mathrm{mM}$ glucose $+2.5 \mathrm{mM} n$-hexadecane as substrate. The siderophore concentration in all experiments was measured over several days using the standard CAS (Chrome Azurol S) assay. All experiments were done in triplicate (A) or duplicate $(\mathbf{B}, \mathbf{C})$.

V. paradoxus EPS showed siderophore production not only with glucose, succinate, and benzoate but also with $n$-hexadecane (Figure 2A). The highest concentration of siderophore was reached with glucose $(750 \mu \mathrm{M})$, followed by benzoate $(500 \mu \mathrm{M}), n$-hexadecane $(500 \mu \mathrm{M})$, and succinate $(140 \mu \mathrm{M})$. The alkane-containing cultures started siderophore production not until day five, but the siderophore concentration remained at a constantly high level over the monitored period. During the siderophore production with V. paradoxus, we suspected that the siderophores and/or the siderophore production might be sensitive to light exposure. An experiment with lightened and darkened cultures showed a significantly increased maximal siderophore concentration in the darkened tubes (Figure 2B) supporting the previous suggestion. The formation of photoproducts needs yet to be confirmed. Nevertheless, siderophore producing cultures, siderophore-containing culture supernatants and siderophore extracts were protected from light in further experiments. 
A

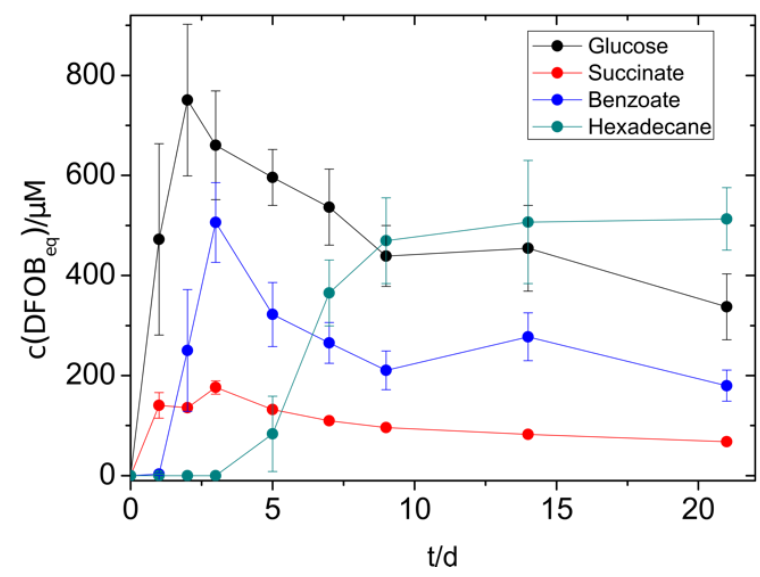

B

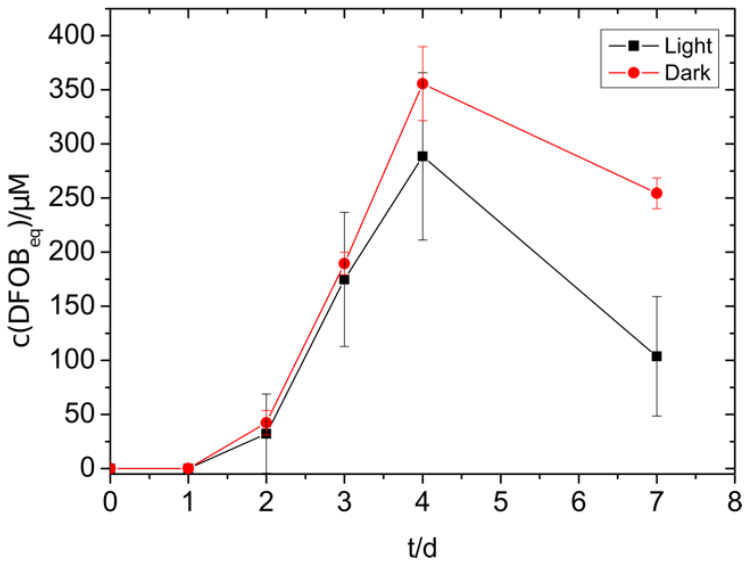

Figure 2. Siderophore production of $V$. paradoxus with different substrates $(5 \mathrm{mM})(\mathbf{A})$ and with benzoate $(5 \mathrm{mM})$ in the presence or absence of light. (B) Experiments were done in triplicates. The concentration of siderophores was measured using the standard CAS assay.

The siderophores in culture supernatants of R. erythropolis B7g (Sid-ReB7g), P. chlororaphis DSM 50083 (Sid-PcDSM), and V. paradoxus EPS (Sid-VpEPS), which were stored at $4{ }^{\circ} \mathrm{C}$, showed a comparable decrease in iron binding capacity over the time (Figure 3). However, the measurable concentration decrease (detected with CAS assay) appears to be slow and linear for Sid-PcDSM, while 20-25\% less siderophore was already detected after the first month for Sid- $V p$ EPS and Sid-ReB7g. Nevertheless, $40-60 \%$ of the initial CAS activity could be measured for all siderophores in culture supernatants after eight months without any addition of stabilizing supplements or other preventive actions. This indicates a good stability of the siderophores. The methanolic extract of Sid- $V p$ EPS seems to be even more stable.

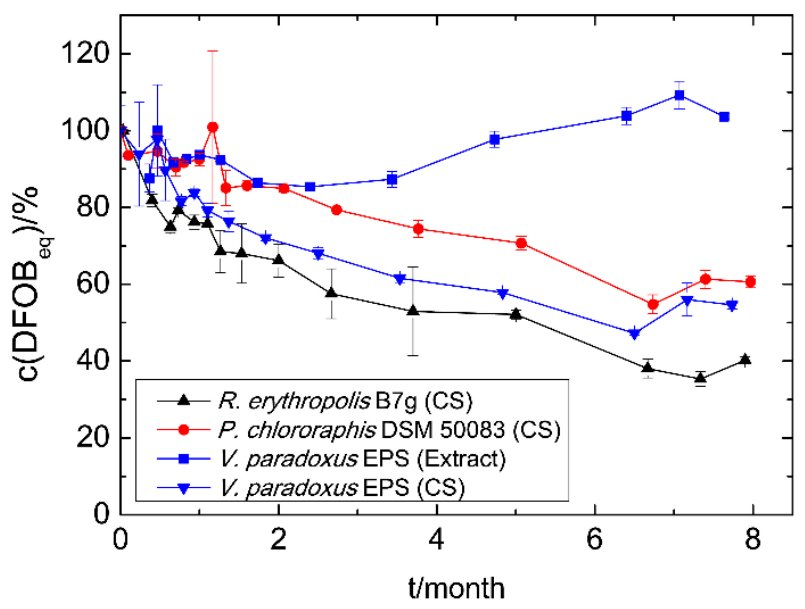

Figure 3. Time-dependent siderophore concentration of culture supernatants (CS) and siderophore extracts. Cell-free culture supernatants and the methanolic extract were stored at $4{ }^{\circ} \mathrm{C}$. The concentration was measured using the CAS assay as $\mathrm{DFOB}_{\mathrm{eq}}$. The initial siderophore concentration represents $100 \%$ and varied among the different strains and methods: Sid-ReB7g $780 \mu \mathrm{M}$, Sid-PcDSM $110 \mu \mathrm{M}$, Sid- $V p$ EPS (CS) $490 \mu \mathrm{M}$, and Sid- $V p$ EPS (extract) $1500 \mu \mathrm{M}$.

\subsection{Siderophore Attachment to Solid-Phase Extraction Columns}

To remove metals from aqueous solutions, immobilization of the siderophores to solid phases simplifies the application. For that purpose, attachment of siderophores to solid-phase extraction (SPE) columns based on $\mathrm{C}_{18}$ and silica was investigated in a test scale (100 mg solid material) with culture supernatants containing Sid-PcDSM, Sid-ReB7g, Sid- 
$V p$ EPS, or the siderophores produced by N. simplex 3E (Sid-Ns3E). The results are shown in Figure S12. Siderophores could be attached to both materials in case of Sid-PcDSM and Sid-ReB7g; Sid-VpEPS and Sid-Ns3E showed promising results with $\mathrm{C}_{18}$ columns. However, the attachment efficiency was highly $\mathrm{pH}$-dependent with the best results at $\mathrm{pH}$ 2.0. The $\mathrm{C}_{18}$ material was, in general, less $\mathrm{pH}$-dependent and showed a better overall attachment. Therefore, the $\mathrm{C}_{18}$ SPE columns were chosen for further experiments. An amount of up to $8.7 \mu \mathrm{mol}$ Sid-ReB7g (13.9 $\mu \mathrm{mol}$ loaded), $3.3 \mu \mathrm{mol}$ Sid-PcDSM (5.3 $\mu \mathrm{mol}$ loaded), and $4 \mu \mathrm{mol}$ Sid-Ns3E (13.3 $\mu$ mol loaded) was immobilized to the solid material. Although the first attachment experiments revealed good results for Sid-PcDSM, the siderophore proved not to be suitable for the attachment on the $\mathrm{C}_{18}$ columns due to a weak binding on the material. When the Sid-PcDSM-columns were rinsed with several column volumes of solution, the bound siderophore was stepwise washed out over the time (data not shown). Since the siderophore production with $V$. paradoxus EPS led to reproducibility problems in larger culture volumes, the metal binding experiments with the siderophore-loaded columns were only continued with Sid-Ns3E and Sid-ReB7g. The metal binding experiments were carried out in different setups: The metals were applied as single solutions (Figure $4 \mathrm{~A}$ ), mixed solutions including Fe(III) (Figures $4 \mathrm{~A}$ and $5 \mathrm{~B}$ ), or iron-free mixed solutions (Figures $4 \mathrm{~B}$ and $5 \mathrm{C}$ ).

A

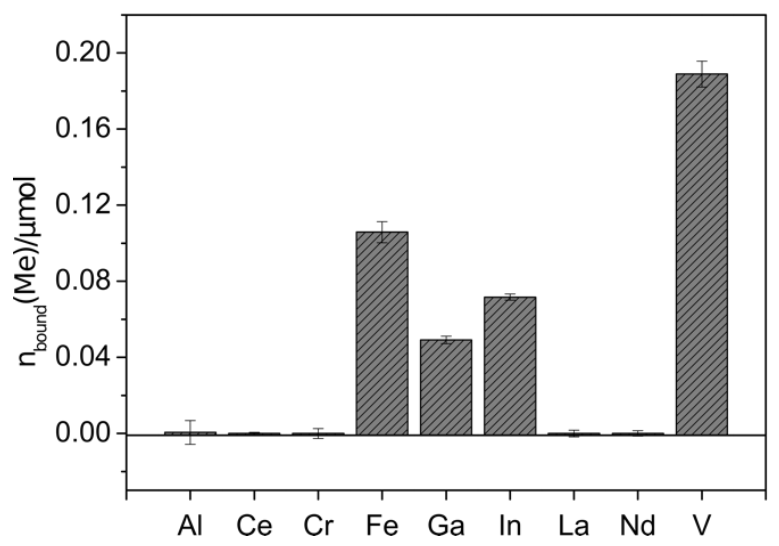

$\mathrm{B}$

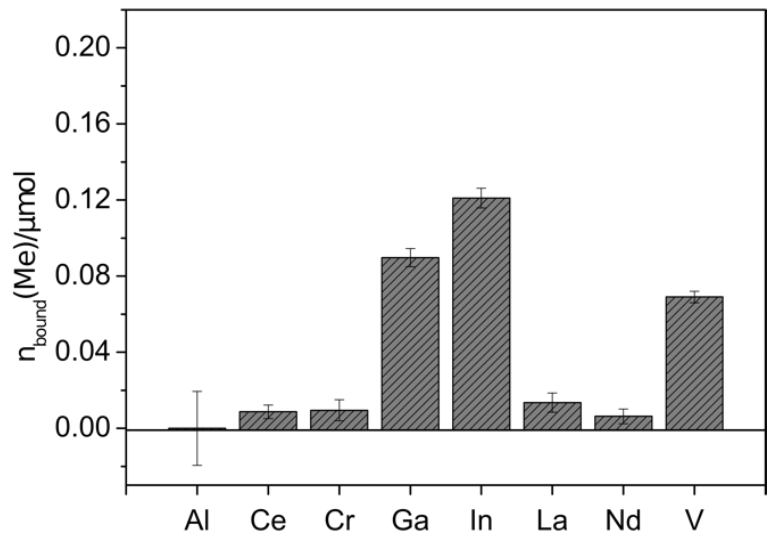

Figure 4. Metal binding by Sid-Ns3E-loaded columns. Mixed metal solutions with (A) and without (B) iron were applied to the $2.6 \mu \mathrm{mol} \mathrm{DFOB}_{\mathrm{eq}}$-loaded $\mathrm{C}_{18}$ columns. The metal solutions contained $0.6 \mu \mathrm{mol}$ of each different metal ion. $\mathrm{C}_{18}$ columns without siderophore served as blank samples. The metal concentration in the flow-through was detected using inductively coupled plasma mass spectrometry (ICP-MS xseries 2, Thermo Scientifc). The total amount of metal bound to the immobilized siderophore columns is visualized. All experiments were done in duplicate.

The metal extraction experiment with Sid-Ns3E-loaded columns showed the extraction of $\mathrm{Fe}, \mathrm{Ga}$, In, and V, with higher extraction efficiency for In and $\mathrm{Ga}$ in the absence of Fe (Figure 5). Almost no removal could be detected with aluminum and the rare earth elements. The affinity of Sid-Ns3E to In(III) seems to be higher than to Ga(III) and both metals were extracted in comparable higher amounts in relation to present iron, considering the known high affinity of desferrioxamines to Fe(III). The overall extracted amount of metals was much lower with Sid-Ns3E than with Sid-ReB7g-loaded columns. 


\section{A}

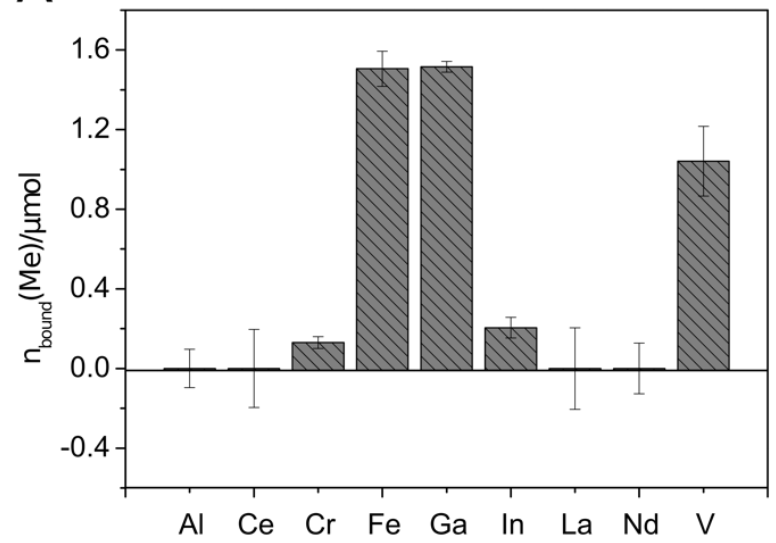

B

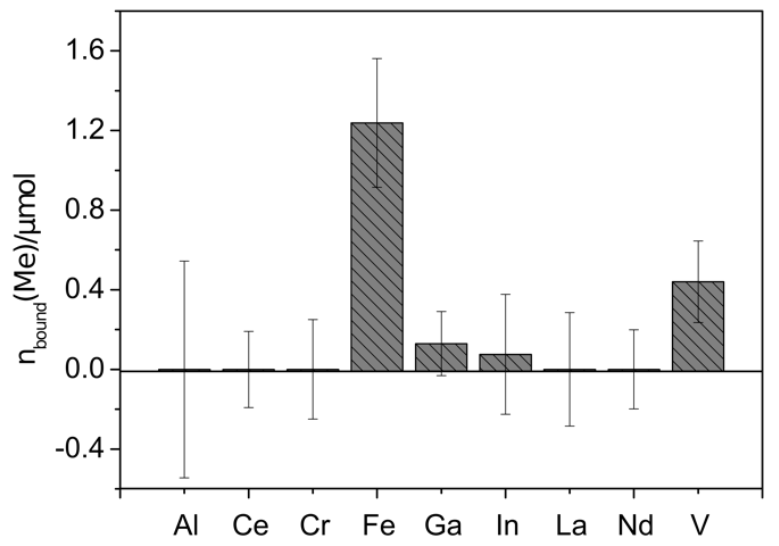

C

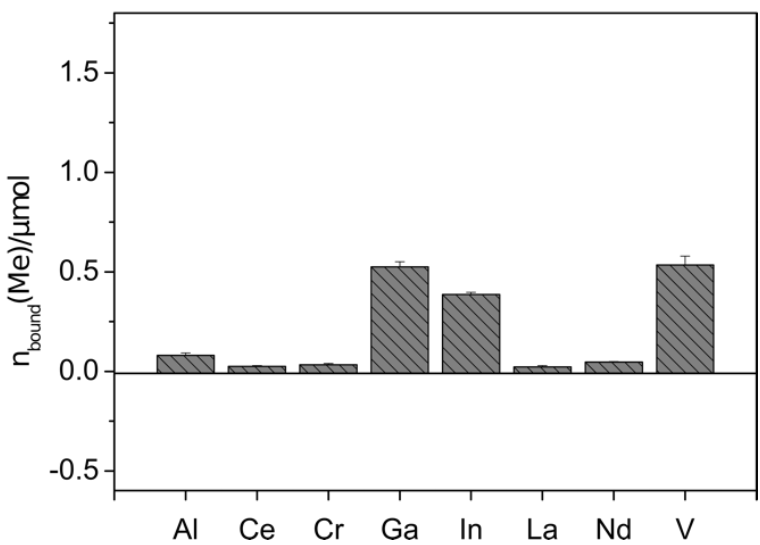

Figure 5. Metal binding by Sid-ReB7g-loaded columns. Metal solutions were applied containing either one single metal ion $(14 \mu \mathrm{mol})(\mathbf{A})$, mixed metal ions (each $14 \mu \mathrm{mol})(\mathbf{B})$, or mixed metal ions (each $2 \mu \mathrm{mol})(\mathbf{C})$. $\mathrm{C}_{18}$ columns without siderophore served as blank samples. The metal concentration in the flow-through was detected using ICP-MS. The total amount of metal bound to the immobilized siderophore columns is visualized. All experiments were done in duplicates.

The application of metal solutions on Sid-ReB7g-loaded columns indicated that the immobilized siderophore(s) from Rhodococcus were able to complex iron and gallium to a similar extend when only a single metal was applied (Figure 5A). Additionally, indium and chromium complexed with the Sid-ReB7g as well as comparably high amounts of vanadium. Again, no removal could be detected for aluminum and the rare earth elements. The experiments with mixed metal solutions showed the binding of the same metals but gave an interesting insight into the binding competition. We observed a strong preference for $\mathrm{Fe}(\mathrm{III})$, leading to an amount of only $10 \%$ bound $\mathrm{Ga}$ (III) compared to bound $\mathrm{Fe}(\mathrm{III})$. Moreover, a stepwise application of the mixed metal solution showed that the amount of already bound gallium decreased with further addition of metal solution, while the amount of iron continued to increase (data not shown). This additionally argues for a higher affinity of Sid-ReB7g toward iron, as this metal seems to be able to displace gallium from the siderophore binding site. Vanadium and little amounts of indium were still complexed on the Sid-column. However, it needs to be mentioned that the high concentration of ions in the mix led to higher deviations from the metal recovery, but the overall trend as described seems valid. In a third experiment, the metals were applied in a larger, lowconcentrated volume, which was pumped over the column and provides a more realistic scenario for potential applications such as wastewater treatment and metal recovery from low concentrated solutions. Additionally, a metal solution without iron was used to observe 
the competition in an iron-free environment. The results showed the binding of $\mathrm{Ga}$, In, and $\mathrm{V}$ in almost similar amounts.

The immobilized siderophores could be stored at $4{ }^{\circ} \mathrm{C}$ in acidified water ( $\mathrm{pH}$ 2.0). After 12 days (Sid-Ns3E) and 14 days (Sid-Re3E), no loss in metal binding capacity was noticed (data not shown).

\section{Discussion}

The steadily increasing demand on various metals and metalloids for our current lifestyle asks for novel strategies to enrich those elements from various streams such as low-concentrated solutions from waste streams or processing industries. Often, those nonpregnant or metal-rich solution were not identified as a source of valuable metals. However, this changed in recent years, and the various methods that might be used to extract metals or metalloids from those sources include fractional precipitation, crystallization, and solvent extraction $[1,64]$. All of those methods have advantages and disadvantages as reviewed in the given references. However, a critical point is that the selectivity is often low, especially in the presence of iron ions. This is problematic, as then the only concentration of a mixture but not a selective enrichment of target elements can be achieved. Here, solvent extraction is a promising route, as the formulation of novel highly selective chelators can circumvent this problem and allows the enrichment of target elements such as REE [65-67]. These chelators can be of synthetic or natural origin. The latter means the use of selected siderophores of microbial origin [5] and was recently reviewed and provides various possibilities [4]. Either siderophores can selectively bind iron and remove it prior further processing or they can directly enrich a target element. The progress in identifying and describing novel siderophores for selective metal enrichment achieved within this project is discussed in the following section. In order to allow easy comparison to references, we used the commercially produced and applied siderophore DFOB as reference compound.

Due to their high metal binding ability, siderophores have a great potential for application in the recovery of valuable metals. Therefore, it is of great importance to identify suitable siderophores and investigate options for efficient use. To extend the knowledge on metal binding siderophores from soil bacteria, we screened several strains for siderophore production and metal-binding ability with selected metals using different CAS assay variants. Most strains showed siderophore production to a varying extent of up to $600 \mu \mathrm{M}$ $\mathrm{DFOB}_{\text {eq. }}$. This is not surprising since siderophore production of different amounts is known for many soil bacteria including species of some of the investigated genera $[5,10,48,68-70]$. The detected amounts often do not reflect the full potential of siderophore production since it is dependent on carbon and energy sources, different stressors, and growth conditions of the organisms [62,63], which could not be considered and optimized individually for each strain during the screening. The limited amount of phosphate in the SM-PP medium, which was necessary to minimize the undesired interference with the CAS assay solution [24,27], led in some cases to low cell growth and consequently lower siderophore production in the test tubes. This may also be one factor that could explain the negative results with the liquid CAS assay for S. fribergensis, although yellow halos on the CAS agar plates clearly indicated siderophore production. When comparing the determined concentrations among the strains, it has to be considered that the assay delivers only semiquantitative results pertaining to the reaction with the used standard siderophore DFOB. Due to different molecule sizes, binding affinity, chelation chemistry, and ligand-to-cation stoichiometries of the different siderophores, the real siderophore concentration can deviate from the determined values. Considering the lack of knowledge regarding siderophore structure and chemistry of the tested subjects, the determination of the real siderophore concentrations would not be possible anyway. Therefore, the CAS assay using culture supernatants proved to be a fast and simple instrument to get an overview of the siderophore production and to identify good siderophore producers.

The optimization study of the siderophore production of four selected strains showed that the siderophore amount could be increased under optimal conditions. Notably, 
R. erythropolis produced high amounts of Sid-ReB7g (up to $2.2 \mathrm{mM} \mathrm{DFOB}$ eq). Due to the identification of two different heterobactin-like structures (Table S6), and thus various size of the siderophores, the exact yield could not be determined. However, on basis of the bioinformatical prediction assuming the production of one or more heterobactinlike siderophore and a 1:1 ligand to $\mathrm{Fe}(\mathrm{III})$ ratio of both heterobactin B/S2 and the assay standard DFOB [50,71] (deferoxamine mesylate salt $\mathrm{M}=656 \mathrm{~g} / \mathrm{mol}$, Sigma Aldrich), the produced amount of Sid-ReB7g would be around 1.0-1.5 g/L, which is close to the yield of the industrial important siderophore producer S. pilosus [72]. The carbon source had a high influence on the siderophore amount, rapidity of the synthesis, and the decrease after reaching a maximal concentration of all four strains. Succinic acid/succinate has been reported to be the favorable carbon source for siderophore production in pseudomonads and for pyoverdine production $[62,63,73]$. Surprisingly, cultures of $P$. chlororaphis DSM 50083 containing succinate showed a much lower siderophore production compared to cultures grown on glucose or benzoate. A similar result was observed with $N$. simplex, although desferrioxamine siderophores are proposed to be synthesized from L-lysine and succinate units [74]. Therefore, succinate was expected to be a good substrate for desferrioxamine production in N. simplex as well. The desferrioxamine producing Gordonia rubripertincta CWB2 for instance showed a similar amount of siderophore with either glucose or succinate, although the biomass was higher in glucose-containing medium [18]. Obviously, succinate was good for siderophore production, but no good carbon source was found for G. rubripertincta. V. paradoxus was the only one of the four tested strains who yielded high amounts (up to $500 \mu \mathrm{M} \mathrm{DFOB}$ eq) of siderophore with $n$-hexadecane. The production was much slower, but it stayed on a constantly high level after several days, which might be interesting if a constant monitoring of the siderophore amount is not possible. Another interesting observation for the $V$. paradoxus cultures was the higher siderophore concentration in the absence of light than in the presence of light. Although the photolysis of the siderophores has yet to be proved, photoreactive characteristics are likely and have been described previously for siderophores from Variovorax species. The ferric form of variochelin from $V$. boronicumulans BAM- 48 formed two photoproducts after exposition to direct sunlight, an aldehyde resulting from decarboxylation of the $\beta$-hydroxy aspartate residue as well as a second product probably resulting from a more intensive cleavage reaction [53]. Light-induced cleavage and iron reduction were also observed with the ferric complex of imaqobactin from the arctic bacterium Variovorax sp. RKJM285 [54]. Next to variochelin, imaqobactin, and a few other siderophores from plant-associated bacteria [75,76], photoactive siderophores have mainly been reported from marine bacteria $[77,78]$.

After optimizing the siderophore production process, the siderophore-containing culture supernatants of $N$. simplex, R. erythropolis, and P. chlororaphis were loaded onto to small SPE columns (100 mg column material) driven by the desire to obtain immobilized siderophores. The preparation of pure siderophores is a cost-intensive process which is reflected in the high prices for commercially available siderophores (Merck: DFOE from Streptomyces antibioticus $9 \mathrm{mg} 222 €$, pyoverdines from Pseudomonas fluorescens, $1 \mathrm{mg} 206 €$, enterobactin from Escherichia coli $1 \mathrm{mg} 270 €$, deferriferrichrome from Ustilago sphaerogena $5 \mathrm{mg} 342 €$ ). Siderophore-rich culture supernatants, which were repeatedly pumped over the columns instead of purified siderophores, were used with the intention to reduce the costs for a potential application. The immobilization was successful for Sid-ReB7g from R. erythropolis and Sid-Ns3E from N. simplex, but no proper attachment could be achieved for Sid-PcDSM from P. chlororaphis. The latter was slowly washed out when water or metal solution of greater volumes were applied to the siderophore-loaded columns. For Sid-PcDSM, another immobilization procedure such as the embedding in sol-gel glass might deliver more promising results. Sol-gel glass (tetramethyl orthosilicate) doped with pyoverdine from $P$. fluorescent has been reported to tolerate the treatment with solutions of different $\mathrm{pH}$ in a flow cell without leaching of the siderophore [13].

To test the potential of the siderophore-loaded $C_{18}$ column for metal extraction, metal solutions with different concentrations were applied, containing trivalent $\mathrm{Al}, \mathrm{Ga}, \mathrm{In}, \mathrm{Fe}, \mathrm{V}$, 
$\mathrm{Ce}, \mathrm{Cr}, \mathrm{La}$, and $\mathrm{Nd}$ ions. The removal of $\mathrm{Fe}, \mathrm{Ga}$, In, and $\mathrm{V}$ could be obtained with both SidReB7g as well as Sid-Ns3E-loaded columns. The good binding of iron is in accordance with the literature and was expected since iron acquisition is supposed to be the main physiological role of siderophores and hydroxamate groups exhibit high affinity to $\mathrm{Fe}(\mathrm{III})$ [3,79-81]. However, little is known about the binding affinity of the siderophores of rhodococci besides the fact that the siderophore of $R$. erythropolis $\mathrm{S} 43$, a close relative of $R$. erythropolis $\mathrm{B} 7 \mathrm{~g}$, might be involved in arsenic binding [29]. However, during our initial screening, we found that most rhodococci, which mostly produce heterobactin siderophores, are able to bind to $\mathrm{V}$ from the respective CAS complex; hence, it might be a hint toward a heterobactin- $\mathrm{V}$ complex formation to be investigated in the future (see Table 1). The results from the metal binding study with the immobilized siderophore Sid-ReB7g indicate an overall binding affinity of Sid-ReB7g of $\mathrm{Fe}>\mathrm{Ga} / \mathrm{V}>\mathrm{In}>\mathrm{Cr}$ with a higher extracted amount of $\mathrm{Ga}$ in the simple metal binding experiment but higher or equal amount of bound $\mathrm{V}$ with mixed metal solutions. Immobilized Sid-Ns3E showed comparable binding affinities but preferred In over Ga. The metal binding spectrum of the Nocardioides siderophore corresponds to the literature, assuming the production of desferrioxamine siderophores. Apart from iron, DFOB and DFOE have been reported to form stable complexes with $\mathrm{Ga}, \mathrm{Al}$, In [82-84], $\mathrm{V}$ [83,85], Cr [86], and REE [87]. DFOB exhibits higher binding affinities towards Ga(III) $\left(\log \beta_{110}=28.1\right)$ than $\operatorname{In}(\mathrm{III})\left(\log \beta_{110}=20.1\right)$ [82]. Although the $\beta_{110}$ binding constant only expresses the binding affinities of the fully deprotonated form under certain conditions (which do not necessarily match the conditions of real binding experiments), the stronger preference of Sid-Ns3E to In could indicate that the produced siderophore of Nocardioides simplex is not mainly DFOB. With the used method, the ability to bind $\mathrm{Al}(\mathrm{III})$ could be confirmed with neither Sid-ReB7g nor Sid-Ns3E in the metal binding experiment with immobilized siderophores. Since the decolorization of the Al-CAS assay indicated Al(III) complexation during the screening experiment, this is in contrast to our expectations. Al(III) shows a high similarity to $\mathrm{Fe}$ (III) and $\mathrm{Ga}$ (III) and is reported to form stable complexes with many siderophores, including desferrioxamines [82,88-90]. Therefore, further experiments are necessary to elucidate the $\mathrm{Al}(\mathrm{III})$ binding ability. The siderophore-loaded columns were not able to extract rare earth elements in a sufficient way. An explanation could be found in the large ionic radii of REE, making them too bulky for a sufficient coordination resulting in low binding affinities [87]. A more promising result is the high removal of vanadium from metal solutions. The formation of colored vanadium complexes has been reported for $\mathrm{DFOB}$ with $\mathrm{V}(\mathrm{V})$ as $\mathrm{VO}_{4}{ }^{3-}$ and $\mathrm{V}(\mathrm{IV})$ as $\mathrm{VO}^{2+}$ ion $[85,91]$ with low binding affinities. However, the binding of $\mathrm{V}$ and Mo is widely known for siderophores from nitrogen-fixing bacteria, which complex these metals with exceptionally high stabilities $[92,93]$. The overall results confirm the potential of the immobilized siderophores for the recovery of metals such as Ga, In, and V from low concentrated waters. For instance, the recycling of Ga from wastewater of the wafer fabrication industry is a promising option to apply the developed system. Recycling ensures the future availability of this critical valuable metal, but conventional methods like solvent extraction processes [94], precipitation [95], and ion exchangers [96] failed in respect to an economic recovery due to low Ga concentrations (less than $100 \mathrm{mg} / \mathrm{L}$ ) and contaminants such as $\mathrm{Zn}$ (II) and $\mathrm{Ca}(\mathrm{II})$ [84,97]. Another promising application could be the recovery of $\mathrm{V}$ from seawater, which is the second most abundant dissolved transition metal in seawater with concentrations of about $30 \mathrm{nM}$ [98]. However, the proposed system of this study needs to be scaled up and tested with real water samples. Another important aspect is the recovery of the siderophore-loaded columns to create a recyclable system. The application of EDTA has demonstrated to regenerate desferrioxamines from the corresponding Ga-complexes [84] and is worth investigating with the immobilized siderophores.

In summary, we present the search for a high yield siderophore with the ability to complex valuable critical metals such as Ga, In, V, and REE, the immobilization of selected siderophores to SPE columns, and a proof-of-concept study for the siderophore-based recovery of critical metals from aqueous solutions. Although further research is necessary 
to generate a fully developed system, the immobilized siderophores of $R$. erythropolis and N. simplex were able to recover $\mathrm{Ga}$, In, and V, opening doors in the recovery of critical metals.

Supplementary Materials: The following are available online at https://www.mdpi.com/2076 $-2607 / 9 / 1 / 111 / s 1$, Table S1: Results of the screening with different CAS agar plates and liquid CAS assay, Figure S1: Experimental setup of siderophore attachment to $C_{18}$ solid-phase extraction columns, Figure S2: Workflow of cultivation, supernatant harvest, siderophore attachment and metal binding examination in bound state, Figure S3: Organization of the biosynthesis gene cluster of R. erythropolis B7g, Figure S4: Organization of the biosynthesis gene cluster of V. paradoxus and other Variovorax sp., Figure S5: Mass spectrum of the siderophores of Variovorax paradoxus EPS, Table S2: Comparison of the genome sequences of $P$. chlororaphis DSM50083, Figure S6: Phylogenetic tree of Pseudomonas chlororaphis relatives., Figure S7: Phylogenetic tree of Nocardioides simplex relatives, Figure S8: Organization of the achromobactin biosynthesis gene clusters in P. chlororaphis DSM 50083 and P. syringae B728a, Figure S9: Organization of the pyoverdine biosynthesis gene cluster in P. chlororaphis DSM 50083, P. aeruginosa PAO1, and P. fluorescens SBW25, Figure S10: Organization of the biosynthesis gene cluster in N. simplex $3 \mathrm{E}$ and other strains containing desferrioxamine biosynthesis gene cluster, Table S3: Optical density at inoculation and at stationary stage as reference for bacterial growth under different growth condition, Figure S11: Siderophore production of N. simplex 3E and R. erythropolis B7g with different substrates and SM-PP medium, Figure S12: Siderophore attachment on solid-phase extraction columns, Table S4: Liquid chromatography gradient, Table S5: Siderophores detected in XAD extracts of N. simplex 3E, and Table S6: Siderophores detected in XAD extracts of R. erythropolis B7g.

Author Contributions: Conceptualization, D.T. and M.H.; methodology, M.H. and L.M.; formal analysis, M.H., T.H., and L.M.; investigation, M.H., L.M., T.H., S.H., K.J. and C.H.R.S.; resources, D.T. and J.E.B.; writing—original draft preparation, M.H. and T.H.; writing—review and editing, D.T., L.M., T.H., C.H.R.S. and J.E.B.; visualization, M.H., T.H., K.J. and L.M.; supervision, D.T.; project administration, D.T.; funding acquisition, D.T. All authors have read and agreed to the published version of the manuscript.

Funding: This research was founded by the Federal Ministry of Education and Research (BMBF) through the project BakSolEx (033R147). JEB gratefully acknowledges funding from the German Research Foundation (BA 4193/6-1) and from the German federal state of North Rhine-Westphalia (NRW) for the mass spectrometer (Forschungsgroßgeräte der Länder).

Data Availability Statement: The genome data presented in this study are openly available in DDBJ/ENA/GenBank at the reference under the accession JADCLH000000000 (P. chlororaphis, BioSample SAMN16418570) and JADCLI000000000 (N. simplex, BioSample SAMN16418572).

Acknowledgments: The authors thank M. Schlömann (TU Bergakademie Freiberg) for the continuous support.

Conflicts of Interest: The authors declare no conflict of interest. The funders had no role in the design of the study; in the collection, analyses, or interpretation of data; in the writing of the manuscript, or in the decision to publish the results.

\section{References}

1. Fröhlich, P.; Lorenz, T.; Martin, G.; Brett, B.; Bertau, M. Valuable Metals-Recovery Processes, Current Trends, and Recycling Strategies. Angew. Chem. 2017, 56, 2544-2580. [CrossRef] [PubMed]

2. Verma, T.; Maurya, A.; Tripathi, M.; Garg, S.K. Mycoremediation: An alternative treatment strategy for heavy metal-laden wastewater. In Developments in Fungal Biology and Applied Mycology; Satyanarayana, T., Deshmukh, S.K., Johri, B.N., Eds.; Springer: Singapore, 2017; pp. 315-340. ISBN 978-981-10-4768-8.

3. Johnstone, T.C.; Nolan, E.M. Beyond Iron: Non-Classical Biological Functions of Bacterial Siderophores. Dalton Trans. 2015, 44, 6320-6339. [CrossRef]

4. Hofmann, M.; Retamal-Morales, G.; Tischler, D. Metal Binding Ability of Microbial Natural Metal Chelators and Potential Applications. Nat. Prod. Rep. 2020, 37, 1262-1283. [CrossRef]

5. Hider, R.C.; Kong, X. Chemistry and Biology of Siderophores. Nat. Prod. Rep. 2010, 27, 637-657. [CrossRef] [PubMed] 
6. Bobrov, A.G.; Kirillina, O.; Fetherston, J.D.; Miller, M.C.; Burlison, J.A.; Perry, R.D. The Yersinia Pestis Siderophore, Yersiniabactin, and the ZnuABC System Both Contribute to Zinc Acquisition and the Development of Lethal Septicaemic Plague in Mice. Mol. Microbiol. 2014, 93, 759-775. [CrossRef] [PubMed]

7. Ghssein, G.; Matar, S. Chelating Mechanisms of Transition Metals by Bacterial Metallophores "Pseudopaline and Staphylopine": A Quantum Chemical Assessment. Computation 2018, 6, 56. [CrossRef]

8. Chaturvedi, K.S.; Hung, C.S.; Crowley, J.R.; Stapleton, A.E.; Henderson, J.P. The Siderophore Yersiniabactin Binds Copper to Protect Pathogens during Infection. Nat. Chem. Biol. 2012, 8, 731-736. [CrossRef]

9. Kenney, G.E.; Rosenzweig, A.C. Chemistry and Biology of the Copper Chelator Methanobactin. ACS Chem. Biol. 2012, 7, 260-268. [CrossRef]

10. Braud, A.; Jézéquel, K.; Léger, M.-A.; Lebeau, T. Siderophore Production by Using Free and Immobilized Cells of Two Pseudomonads Cultivated in a Medium Enriched with Fe and/or Toxic Metals (Cr, Hg, Pb). Biotechnol. Bioeng. 2006, 94, 1080-1088. [CrossRef]

11. Braud, A.; Jézéquel, K.; Lebeau, T. Impact of Substrates and Cell Immobilization on Siderophore Activity by Pseudomonads in a $\mathrm{Fe}$ and/or Cr, Hg, Pb Containing-Medium. J. Hazard. Mater. 2007, 144, 229-239. [CrossRef] [PubMed]

12. De Gregorio, P.R.; Michavila, G.; Ricciardi Muller, L.; de Souza Borges, C.; Pomares, M.F.; Saccol de Sá, E.L.; Pereira, C.; Vincent, P.A. Beneficial Rhizobacteria Immobilized in Nanofibers for Potential Application as Soybean Seed Bioinoculants. PLoS ONE 2017, 12, e0176930. [CrossRef] [PubMed]

13. Barrero, J.M.; Cámara, C.; Pérez-Conde, M.C.; José, C.S.; Fernández, L. Pyoverdin-Doped Sol-Gel Glass for the Spectrofluorimetric Determination of Iron(III). Analyst 1995, 120, 431-435. [CrossRef]

14. Chung Chun Lam, C.K.S.; Jickells, T.D.; Richardson, D.J.; Russell, D.A. Fluorescence-Based Siderophore Biosensor for the Determination of Bioavailable Iron in Oceanic Waters. Anal. Chem. 2006, 78, 5040-5045. [CrossRef]

15. Hogon, H. Measuring Oceanic Iron Content in a New Light. Photon. Spectra 2006, 40, 32-34.

16. Roy, E.G.; Jiang, C.; Wells, M.L.; Tripp, C. Determining Subnanomolar Iron Concentrations in Oceanic Seawater Using a Siderophore-Modified Film Analyzed by Infrared Spectroscopy. Anal. Chem. 2008, 80, 4689-4695. [CrossRef]

17. Su, B.-L.; Moniotte, N.; Nivarlet, N.; Chen, L.-H.; Fu, Z.-Y.; Desmet, J.; Li, J. Fl-DFO Molecules@mesoporous Silica Materials: Highly Sensitive and Selective Nanosensor for Dosing with Iron Ions. J. Colloid Interface Sci. 2011, 358, 136-145. [CrossRef]

18. Schwabe, R.; Anke, M.K.; Szymańska, K.; Wiche, O.; Tischler, D. Analysis of Desferrioxamine-like Siderophores and Their Capability to Selectively Bind Metals and Metalloids: Development of a Robust Analytical RP-HPLC Method. Res. Microbiol. 2018, 169, 598-607. [CrossRef]

19. Yehuda, Z.; Hadar, Y.; Chen, Y. Immobilization of Fe Chelators on Sepharose Gel and Its Effect on Their Chemical Properties. J. Agric. Food Chem. 2003, 51, 5996-6005. [CrossRef]

20. Yehuda, Z.; Hadar, Y.; Chen, Y. FeDFOB and FeEDDHA Immobilized on Sepharose Gels as an Fe Sources to Plants. Plant Soil 2012, 350, 379-391. [CrossRef]

21. Horowitz, D.; Margel, S.; Shimoni, T. Iron Detoxification by Haemoperfusion through Deferoxamine-Conjugated AgarosePolyacrolein Microsphere Beads. Biomaterials 1985, 6, 9-16. [CrossRef]

22. Moscatello, N.; Swayambhu, G.; Jones, C.H.; Xu, J.; Dai, N.; Pfeifer, B.A. Continuous Removal of Copper, Magnesium, and Nickel from Industrial Wastewater Utilizing the Natural Product Yersiniabactin Immobilized within a Packed-Bed Column. Chem. Eng. J. 2018, 343, 173-179. [CrossRef]

23. Cox, C.D. Deferration of Laboratory Media and Assays for Ferric and Ferrous Ions. In Methods in Enzymology; Elsevier Inc.: Amsterdam, The Netherlands, 1994; Volume 235, pp. 315-329.

24. Schwyn, B.; Neilands, J.B. Universal Chemical Assay for the Detection and Determination of Siderophore. Anal. Biochem. 1987, 160, 47-56. [CrossRef]

25. Louden, B.C.; Haarmann, D.; Lynne, A.M. Use of Blue Agar CAS Assay for Siderophore Detection. J. Microbiol. Biol. Educ. 2011, 12, 51-53. [CrossRef] [PubMed]

26. Alexander, D.B.; Zuberer, D.A. Use of Chrome Azurol S Reagents to Evaluate Siderophore Production by Rhizosphere Bacteria. Biol. Fertil. Soils 1991, 12, 39-45. [CrossRef]

27. Shenker, M.; Chen, Y.; Hadar, Y. Rapid Method for Accurate Determination of Colorless Siderophores and Synthetic Chelates. Soil Sci. Soc. Am. J. 1995, 59, 1612-1618. [CrossRef]

28. Mehnert, M.; Retamal-Morales, G.; Schwabe, R.; Vater, S.; Heine, T.; Levicán, G.J.; Schlömann, M.; Tischler, D. Revisiting the Chrome Azurol S Assay for Various Metal Ions. Solid State Phenom. 2017, 262, 509-512. [CrossRef]

29. Retamal-Morales, G.; Mehnert, M.; Schwabe, R.; Tischler, D.; Zapata, C.; Chávez, R.; Schlömann, M.; Levicán, G. Detection of Arsenic-Binding Siderophores in Arsenic-Tolerating Actinobacteria by a Modified CAS Assay. Ecotoxicol. Environ. Saf. 2018, 157, 176-181. [CrossRef]

30. Wiche, O.; Tischler, D.; Fauser, C.; Lodemann, J.; Heilmeier, H. Effects of Citric Acid and the Siderophore Desferrioxamine B (DFO-B) on the Mobility of Germanium and Rare Earth Elements in Soil and Uptake in Phalaris Arundinacea. Int. J. Phytoremediat. 2017, 19, 746-754. [CrossRef]

31. Retamal-Morales, G.; Heine, T.; Tischler, J.S.; Erler, B.; Gröning, J.A.D.; Kaschabek, S.R.; Schlömann, M.; Levicán, G.; Tischler, D. Draft Genome Sequence of Rhodococcus Erythropolis B7g, a Biosurfactant Producing Actinobacterium. J. Biotechn. 2018, 280, 38-41. [CrossRef] 
32. Han, J.-I.; Spain, J.C.; Leadbetter, J.R.; Ovchinnikova, G.; Goodwin, L.A.; Han, C.S.; Woyke, T.; Davenport, K.W.; Orwin, P.M. Genome of the Root-Associated Plant Growth-Promoting Bacterium Variovorax Paradoxus Strain EPS. Genome Announc. 2013, 1. [CrossRef]

33. Hofmann, M.; Heine, T.; Schulz, V.; Hofmann, S.; Tischler, D. Draft Genomes and Initial Characterization of Siderophore Producing Pseudomonads Isolated from Mine Dump and Mine Drainage. Biotechnol. Rep. 2020, 25, e00403. [CrossRef] [PubMed]

34. Weber, T.; Blin, K.; Duddela, S.; Krug, D.; Kim, H.U.; Bruccoleri, R.; Lee, S.Y.; Fischbach, M.A.; Müller, R.; Wohlleben, W.; et al. AntiSMASH 3.0-A Comprehensive Resource for the Genome Mining of Biosynthetic Gene Clusters. Nucleic Acids Res. 2015, 43, W237-W243. [CrossRef] [PubMed]

35. Blin, K.; Shaw, S.; Steinke, K.; Villebro, R.; Ziemert, N.; Lee, S.Y.; Medema, M.H.; Weber, T. AntiSMASH 5.0: Updates to the Secondary Metabolite Genome Mining Pipeline. Nucleic Acids Res. 2019, 47, W81-W87. [CrossRef] [PubMed]

36. Aziz, R.K.; Bartels, D.; Best, A.A.; DeJongh, M.; Disz, T.; Edwards, R.A.; Formsma, K.; Gerdes, S.; Glass, E.M.; Kubal, M.; et al. The RAST Server: Rapid Annotations Using Subsystems Technology. BMC Genom. 2008, 9, 75. [CrossRef]

37. Overbeek, R.; Olson, R.; Pusch, G.D.; Olsen, G.J.; Davis, J.J.; Disz, T.; Edwards, R.A.; Gerdes, S.; Parrello, B.; Shukla, M.; et al. The SEED and the Rapid Annotation of Microbial Genomes Using Subsystems Technology (RAST). Nucleic Acids Res. 2014, 42, D206-D214. [CrossRef]

38. Brettin, T.; Davis, J.J.; Disz, T.; Edwards, R.A.; Gerdes, S.; Olsen, G.J.; Olson, R.; Overbeek, R.; Parrello, B.; Pusch, G.D.; et al. RASTtk: A Modular and Extensible Implementation of the RAST Algorithm for Building Custom Annotation Pipelines and Annotating Batches of Genomes. Sci. Rep. UK 2015, 5, 8365. [CrossRef]

39. Strong, L.C.; Rosendahl, C.; Johnson, G.; Sadowsky, M.J.; Wackett, L.P. Arthrobacter Aurescens TC1 Metabolizes Diverse s-Triazine Ring Compounds. Appl. Environ. Microbiol. 2002, 68, 5973-5980. [CrossRef]

40. Kleeberg, S.B. Isolation, Charakterisierung und Identifizierung von Gram-Positiven Bakterien Mit der Fähigkeit den Umweltschadstoff Styrol Abzubauen und Untersuchungen des Styrolabbauweges Bei Einem Isolat; Besondere Lernleistung Geschwister-Scholl-Gymnasium Nossen: Nossen, Germany, 2010.

41. Heine, T.; Zimmerling, J.; Ballmann, A.; Kleeberg, S.B.; Rückert, C.; Busche, T.; Winkler, A.; Kalinowski, J.; Poetsch, A.; Scholtissek, A.; et al. On the Enigma of Glutathione-Dependent Styrene Degradation in Gordonia Rubripertincta CWB2. Appl. Environ. Microbiol. 2018, 84, e00154-18. [CrossRef]

42. Golovleva, L.A.; Pertsova, R.N.; Evtushenko, L.I.; Baskunov, B.P. Degradation of 2,4,5-Trichlorophenoxyacetic Acid by a Nocardioides Simplex Culture. Biodegradation 1990, 1, 263-271. [CrossRef]

43. Tischler, D.; Gröning, J.A.D.; Kaschabek, S.R.; Schlömann, M. One-Component Styrene Monooxygenases: An Evolutionary View on a Rare Class of Flavoproteins. Appl. Biochem. Biotech. 2012, 167, 931-944. [CrossRef]

44. Sultana, M.; Vogler, S.; Zargar, K.; Schmidt, A.-C.; Saltikov, C.; Seifert, J.; Schlömann, M. New Clusters of Arsenite Oxidase and Unusual Bacterial Groups in Enrichments from Arsenic-Contaminated Soil. Arch. Microbiol. 2012, 194, 623-635. [CrossRef] [PubMed]

45. Retamal-Morales, G.; Mehnert, M.; Schwabe, R.; Tischler, D.; Schlömann, M.; Levicán, G.J. Genomic Characterization of the Arsenic-Tolerant Actinobacterium, Rhodococcus Erythropolis S43. Solid State Phenom. 2017, 262, 660-663. [CrossRef]

46. Seto, M.; Kimbara, K.; Shimura, M.; Hatta, T.; Fukuda, M.; Yano, K. A Novel Transformation of Polychlorinated Biphenyls by Rhodococcus Sp. Strain RHA1. Appl. Environ. Microbiol. 1995, 61, 3353-3358. [CrossRef] [PubMed]

47. Gorlatov, S.N.; Maltseva, O.V.; Shevchenko, V.I.; Golovlava, L.A. Degradation of Chlorophenols by a Culture of Rhodococcus Erythropolis. Mikrobiol. 1989, 802-806.

48. Heine, T.; Mehnert, M.; Schwabe, R.; Tischler, D. Thermochelin, a Hydroxamate Siderophore from Thermocrispum Agreste DSM 44070. Solid State Phenom. 2017, 262, 501-504. [CrossRef]

49. Schwabe, R.; Senges, C.; Bandow, J.; Heine, T.; Lehmann, H.; Schlömann, M.; Levicán, G.; Tischler, D. Cultivation Dependent Formation of Siderophores by Gordonia Rubripertincta CWB2. Microb. Res. 2020, 238, 126481. [CrossRef]

50. Bosello, M.; Zeyadi, M.; Kraas, F.I.; Linne, U.; Xie, X.; Marahiel, M.A. Structural Characterization of the Heterobactin Siderophores from Rhodococcus Erythropolis PR4 and Elucidation of Their Biosynthetic Machinery. J. Nat. Prod. 2013, 76, 2282-2290. [CrossRef]

51. Miranda-CasoLuengo, R.; Coulson, G.B.; Miranda-CasoLuengo, A.; Vázquez-Boland, J.A.; Hondalus, M.K.; Meijer, W.G. The Hydroxamate Siderophore Rhequichelin Is Required for Virulence of the Pathogenic Actinomycete Rhodococcus Equi. Infect. Immun. 2012, 80, 4106-4114. [CrossRef]

52. Johnston, C.W.; Skinnider, M.A.; Wyatt, M.A.; Li, X.; Ranieri, M.R.M.; Yang, L.; Zechel, D.L.; Ma, B.; Magarvey, N.A. An Automated Genomes-to-Natural Products Platform (GNP) for the Discovery of Modular Natural Products. Nat. Commun. 2015, 6 , 1-11. [CrossRef]

53. Kurth, C.; Schieferdecker, S.; Athanasopoulou, K.; Seccareccia, I.; Nett, M. Variochelins, Lipopeptide Siderophores from Variovorax Boronicumulans Discovered by Genome Mining. J. Nat. Prod. 2016, 79, 865-872. [CrossRef]

54. Robertson, A.W.; McCarville, N.G.; MacIntyre, L.W.; Correa, H.; Haltli, B.; Marchbank, D.H.; Kerr, R.G. Isolation of Imaqobactin, an Amphiphilic Siderophore from the Arctic Marine Bacterium Variovorax Species RKJM285. J. Nat. Prod. 2018, 81, 858-865. [CrossRef] [PubMed]

55. Moon, C.D.; Zhang, X.-X.; Matthijs, S.; Schäfer, M.; Budzikiewicz, H.; Rainey, P.B. Genomic, Genetic and Structural Analysis of Pyoverdine-Mediated Iron Acquisition in the Plant Growth-Promoting Bacterium Pseudomonas Fluorescens SBW25. BMC Microbiol. 2008, 8, 7. [CrossRef] [PubMed]

56. Ringel, M.T.; Brüser, T. The Biosynthesis of Pyoverdines. Microb. Cell 2018, 5, 424-437. [CrossRef] [PubMed] 
57. Springer. Microbial Siderophores; Soil Biology; Varma, A., Chincholkar, S.B., Eds.; Springer: Berlin/Heidelberg, Germany, 2007; Volume 12, ISBN 978-3-540-71159-9.

58. Müller, A.; Zähner, H. Stoffwechselprodukte von Mikrooganismen: Ferrioxamine Aus Eubacteriales. Arch. Microbiol. 1968, 62, 257-263.

59. Shtratnikova, V.Y.; Schelkunov, M.I.; Pekov, Y.A.; Fokina, V.V.; Logacheva, M.D.; Sokolov, S.L.; Bragin, E.Y.; Ashapkin, V.V.; Donova, M.V. Complete Genome Sequence of Steroid-Transforming Nocardioides Simplex VKM Ac-2033D. Genome Announc. 2015, 3, e01406-14. [CrossRef]

60. Mehnert, M.; Heine, T.; Sobrado, P.; Tischler, D. Indentification of a gene cluster involved in desferrioxamine biosynthesis in Gordonia rubripertincta and Pimelobacter simplex. In Exploring Microorganisms: Recent Advances in Applied Microbiology; Brown Walker Press: Irvine, CA, USA, 2018; pp. 31-34.

61. Hofmann, M.; Martin del Campo, J.S.; Sobrado, P.; Tischler, D. Biosynthesis of Desferrioxamine Siderophores Initiated by Decarboxylases: A Functional Investigation of Two Lysine/Ornithine-Decarboxylases from Gordonia Rubripertincta CWB2 and Pimelobacter Simplex 3E. Arch. Biochem. Biophys. 2020, 689, 108429. [CrossRef]

62. Bhattacharya, A. Siderophore Mediated Metal Uptake by Pseudomonas Fluorescens and Its Comparison to Iron (III) Chelation. Ceylon J. Sci. Biol. Sci. 2010, 39, 147-155. [CrossRef]

63. Meyer, J.M.; Abdallah, M.A. The Fluorescent Pigment of Pseudomonas Fluorescens: Biosynthesis, Purification and Physicochemical Properties. Microbiology 1978, 107, 319-328. [CrossRef]

64. Zhang, J.; Zhao, B.; Schreiner, B. Solvent extraction in metal hydrometallurgy. In Separation Hydrometallurgy of Rare Earth Elements; Springer International Publishing: Cham, Switzerland, 2016; pp. 55-78. ISBN 978-3-319-28233-6.

65. Deshmane, V.G.; Islam, S.Z.; Bhave, R.R. Selective Recovery of Rare Earth Elements from a Wide Range of E-Waste and Process Scalability of Membrane Solvent Extraction. Environ. Sci. Technol. 2019. [CrossRef]

66. Ni'am, A.C.; Wang, Y.-F.; Chen, S.-W.; Chang, G.-M.; You, S.-J. Simultaneous Recovery of Rare Earth Elements from Waste Permanent Magnets (WPMs) Leach Liquor by Solvent Extraction and Hollow Fiber Supported Liquid Membrane. Chem. Eng. Process. 2020, 148, 107831. [CrossRef]

67. Belova, V.V. Development of Solvent Extraction Methods for Recovering Rare Earth Metals. Theor. Found. Chem. Eng. 2017, 51, 599-609. [CrossRef]

68. Carrano, C.J.; Jordan, M.; Drechsel, H.; Schmid, D.G.; Winkelmann, G. Heterobactins: A New Class of Siderophores from Rhodococcus Erythropolis IGTS8 Containing Both Hydroxamate and Catecholate Donor Groups. Biometals 2001, 14, 119-125. [CrossRef]

69. Bosello, M.; Robbel, L.; Linne, U.; Xie, X.; Marahiel, M.A. Biosynthesis of the Siderophore Rhodochelin Requires the Coordinated Expression of Three Independent Gene Clusters in Rhodococcus Jostii RHA1. J. Am. Chem. Soc. 2011, 133, 4587-4595. [CrossRef]

70. Anttila, J.; Heinonen, P.; Nenonen, T.; Pino, A.; Iwaï, H.; Kauppi, E.; Soliymani, R.; Baumann, M.; Saksi, J.; Suni, N.; et al. Is Coproporphyrin III a Copper-Acquisition Compound in Paracoccus Denitrificans? BBA Bioenerg. 2011, 1807, 311-318. [CrossRef]

71. Cozar, O.; Leopold, N.; Jelic, C.; Chiş, V.; David, L.; Mocanu, A.; Tomoaia-Cotişel, M. IR, Raman and Surface-Enhanced Raman Study of Desferrioxamine B and Its Fe(III) Complex, Ferrioxamine B. J. Mol. Struct. 2006, 788, 1-6. [CrossRef]

72. Chiani, M.; Akbarzadeh, A.; Farhangi, A.; Mehrabi, M.R. Production of Desferrioxamine B (Desferal) Using Corn Steep Liquor in Streptomyces Pilosus. Pakistan J. Biol. Sci. 2010, 13, 1151-1155. [CrossRef]

73. Barbhaiya, H.B.; Rao, K.K. Production of Pyoverdine, the Fluorescent Pigment of Pseudomonas Aeruginosa PAO1. FEMS Microbiol. Lett. 1985, 27, 233-235. [CrossRef]

74. Challis, G.L. A Widely Distributed Bacterial Pathway for Siderophore Biosynthesis Independent of Nonribosomal Peptide Synthetases. ChemBioChem 2005, 6, 601-611. [CrossRef]

75. Rosconi, F.; Davyt, D.; Martínez, V.; Martínez, M.; Abin-Carriquiry, J.A.; Zane, H.; Butler, A.; de Souza, E.M.; Fabiano, E. Identification and Structural Characterization of Serobactins, a Suite of Lipopeptide Siderophores Produced by the Grass Endophyte Herbaspirillum Seropedicae: Siderophores of Herbaspirillum Seropedicae. Environ. Microbiol. 2013, 15, 916-927. [CrossRef]

76. Kreutzer, M.F.; Nett, M. Genomics-Driven Discovery of Taiwachelin, a Lipopeptide Siderophore from Cupriavidus Taiwanensis. Org. Biomol. Chem. 2012, 10, 9338. [CrossRef]

77. Barbeau, K.; Rue, E.L.; Bruland, K.W.; Butler, A. Photochemical Cycling of Iron in the Surface Ocean Mediated by Microbial Iron(Iii)-Binding Ligands. Nature 2001, 413, 409-413. [CrossRef] [PubMed]

78. Barbeau, K.; Rue, E.L.; Trick, C.G.; Bruland, K.W.; Butler, A. Photochemical Reactivity of Siderophores Produced by Marine Heterotrophic Bacteria and Cyanobacteria Based on Characteristic Fe(III) Binding Groups. Limnol. Oceanogr. 2003, 48, 1069-1078. [CrossRef]

79. Ahmed, E.; Holmström, S.J.M. Siderophores in Environmental Research: Roles and Applications. Microb. Biotechnol. 2014, 7, 196-208. [CrossRef] [PubMed]

80. Dertz, E.A.; Raymond, K.N. 8.6-Siderophores and transferrins. In Comprehensive Coordination Chemistry II; McCleverty, J.A., Meyer, T.J., Eds.; Pergamon: Oxford, UK, 2003; pp. 141-168. ISBN 978-0-08-043748-4.

81. Miethke, M.; Marahiel, M.A. Siderophore-Based Iron Acquisition and Pathogen Control. Microbiol. Mol. Biol. Rev. 2007, 71, 413-451. [CrossRef] [PubMed]

82. Evers, A.; Hancock, R.D.; Martell, A.E.; Motekaitis, R.J. Metal Ion Recognition in Ligands with Negatively Charged Oxygen Donor Groups. Complexation of Iron(III), Gallium(III), Indium(III), Aluminum(III), and Other Highly Charged Metal Ions. Inorg. Chem. 1989, 28, 2189-2195. [CrossRef] 
83. Proença, D.N.; Heine, T.; Senges, C.H.R.; Bandow, J.E.; Morais, P.V.; Tischler, D. Bacterial Metabolites Produced under Iron Limitation Lill Pinewood Nematode and Attract Caenorhabditis Elegans. Front. Microbiol. 2019, 10, 2166. [CrossRef]

84. Jain, R.; Fan, S.; Kaden, P.; Tsushima, S.; Foerstendorf, H.; Barthen, R.; Lehmann, F.; Pollmann, K. Recovery of Gallium from Wafer Fabrication Industry Wastewaters by Desferrioxamine B and E Using Reversed-Phase Chromatography Approach. Water Res. 2019, 158, 203-212. [CrossRef] [PubMed]

85. Luterotti, S.; Grdinić, V. Spectrophotometric Determination of Vanadium(V) with Desferrioxamine B. Analyst 1986, 111, 1163-1165. [CrossRef]

86. Duckworth, O.W.; Akafia, M.M.; Andrews, M.Y.; Bargar, J. Siderophore-Promoted Dissolution of Chromium from Hydroxide Minerals. Environ. Sci. Proc. Imp. 2014, 16, 1348-1359. [CrossRef]

87. Christenson, E.A.; Schijf, J. Stability of YREE Complexes with the Trihydroxamate Siderophore Desferrioxamine B at Seawater Ionic Strength. Geochim. Cosmochim. Acta 2011, 75, 7047-7062. [CrossRef]

88. Emery, T. Role of Ferrichrome as a Ferric Ionophore in Ustilago Sphaerogena. Biochemistry 1971, 10, 1483-1488. [CrossRef] [PubMed]

89. Rogers, H.J.; Synge, C.; Woods, V.E. Antibacterial Effect of Scandium and Indium Complexes of Enterochelin on Klebsiella Pneumoniae. Antimicrob. Agents Chemother. 1980, 18, 63-68. [CrossRef] [PubMed]

90. Braud, A.; Hannauer, M.; Mislin, G.L.A.; Schalk, I.J. The Pseudomonas Aeruginosa Pyochelin-Iron Uptake Pathway and Its Metal Specificity. J. Bacteriol. 2009, 191, 3517-3525. [CrossRef] [PubMed]

91. Keller, R.J.; Rush, J.D.; Grover, T.A. Spectrophotometric and ESR Evidence for Vanadium(IV) Deferoxamine Complexes. J. Inorg. Biochem. 1991, 41, 269-276. [CrossRef]

92. Bellenger, J.-P.; Arnaud-Neu, F.; Asfari, Z.; Myneni, S.C.B.; Stiefel, E.I.; Kraepiel, A.M.L. Complexation of Oxoanions and Cationic Metals by the Biscatecholate Siderophore Azotochelin. J. Biol. Inorg. Chem. 2007, 12, 367-376. [CrossRef]

93. Bellenger, J.P.; Wichard, T.; Kustka, A.B.; Kraepiel, A.M.L. Uptake of Molybdenum and Vanadium by a Nitrogen-Fixing Soil Bacterium Using Siderophores. Nat. Geosci. 2008, 1, 243-246. [CrossRef]

94. Nusen, S.; Chairuangsri, T.; Zhu, Z.; Cheng, C.Y. Recovery of Indium and Gallium from Synthetic Leach Solution of Zinc Refinery Residues Using Synergistic Solvent Extraction with LIX 63 and Versatic 10 Acid. Hydrometallurgy 2016, 160, 137-146. [CrossRef]

95. Xu, K.; Deng, T.; Liu, J.; Peng, W. Study on the Recovery of Gallium from Phosphorus Flue Dust by Leaching with Spent Sulfuric Acid Solution and Precipitation. Hydrometallurgy 2007, 86, 172-177. [CrossRef]

96. Zhao, Z.; Yang, Y.; Xiao, Y.; Fan, Y. Recovery of Gallium from Bayer Liquor: A Review. Hydrometallurgy 2012, 125, 115-124. [CrossRef]

97. Løvik, A.N.; Restrepo, E.; Müller, D.B. The Global Anthropogenic Gallium System: Determinants of Demand, Supply and Efficiency Improvements. Environ. Sci. Technol. 2015, 49, 5704-5712. [CrossRef]

98. Rehder, D. Bioanorganische Chemie Des Vanadiums. Leben Ohne Vanadium? Chem. Unserer Zeit 2010, 44, 322-331. [CrossRef] 